\title{
Article \\ Necrotizing Gingivitis: Microbial Diversity and Quantification of Protein Secretion in Necrotizing Gingivitis
}

\author{
Nicolas Gerhard ${ }^{1}$, Thomas Thurnheer ${ }^{1}$ (D), Susanne Kreutzer ${ }^{2}$, Rudolf Dominik Gmür ${ }^{1}$, Thomas Attin ${ }^{1}$, \\ Giancarlo Russo $^{2,+}$ and Lamprini Karygianni ${ }^{1, *,+}$ (D) \\ 1 Clinic for Conservative and Preventive Dentistry, Center of Dental Medicine, University of Zurich, \\ Plattenstrasse 11, 8032 Zurich, Switzerland; nicigerhard@bluewin.ch (N.G.); \\ Thomas.Thurnheer@zzm.uzh.ch (T.T.); nickgmuer@bluewin.ch (R.D.G.); Thomas.Attin@zzm.uzh.ch (T.A.) \\ 2 Functional Genomics Center Zurich, University of Zurich/ETH Zurich, 8057 Zurich, Switzerland; \\ susanne.kreutzer@fgcz.ethz.ch (S.K.); giancarlo.russo@uzh.ch (G.R.) \\ * Correspondence: lamprini.karygianni@zzm.uzh.ch; Tel.: +0041-44-634-3275 \\ + These authors contribute equally to this work.
}

Citation: Gerhard, N.; Thurnheer, T.; Kreutzer, S.; Gmür, R.D.; Attin, T.; Russo, G.; Karygianni, L. Necrotizing Gingivitis: Microbial Diversity and Quantification of Protein Secretion in Necrotizing Gingivitis. Antibiotics 2021, 10, 1197. https://doi.org/ 10.3390/antibiotics 10101197

Academic Editor: Marc Maresca

Received: 14 August 2021

Accepted: 22 September 2021

Published: 1 October 2021

Publisher's Note: MDPI stays neutral with regard to jurisdictional claims in published maps and institutional affiliations.

Copyright: (C) 2021 by the authors. Licensee MDPI, Basel, Switzerland. This article is an open access article distributed under the terms and conditions of the Creative Commons Attribution (CC BY) license (https:// creativecommons.org/licenses/by/ $4.0 /)$.

\begin{abstract}
Necrotizing gingivitis (NG) is a necrotizing periodontal disease that differs from chronic gingivitis (CG). To date, both the microbiological causes and the involved host cytokine response of NG still remain unclear. Here, we investigated corresponding interdental plaque and serum samples from two groups of Chinese patients with CG $(n=21)$ or NG $(n=21)$. The microbiota were studied by $16 \mathrm{~S}$ rRNA Illumina MiSeq sequencing of the microbial metagenome and by assessing quantitatively the abundance of the phylum Bacteroidetes, the genus Prevotella and the species T. forsythia, P. endodontalis, and P. gingivalis using fluorescence in situ hybridization (FISH). With respect to the associated host response, the levels of 30 inflammatory mediators were quantified by multiplex immunoassay analysis. Differential microbial abundance analysis of the two disease groups revealed at the phylum level that Proteobacteria accounted for $67 \%$ of the differentially abundant organisms, followed by organisms of Firmicutes (21\%) and Actinobacteria (9\%). At the species level, significant differences in abundance were seen for 75 species of which 58 species were significantly more abundant in CG patients. Notably, the FISH analysis revealed that Bacteroidetes was the most prevalent phylum in NG. The multiplex cytokine assay showed significant quantitative differences between the disease groups for eight analytes (GM-CSF, G-CSF, IFN- $\alpha$, IL-4, IL-13, TNF- $\alpha$, MIG, and HGF). The G-CSF was found to be the most significantly increased inflammatory protein marker in NG. The next-generation sequencing (NGS) data supported the understanding of NG as a multi-microbial infection with distinct differences to CG in regard to the microbial composition.
\end{abstract}

Keywords: fluorescence in situ hybridization (FISH); 16s rRNA; microbial metagenome; necrotizing gingivitis; multiplex bead array assays (MBAA); cytokines

\section{Introduction}

Necrotizing gingivitis (NG) is a necrotizing periodontal disease with the characteristic presentation of an acute, painful, and destructive process. The progression of the disease can lead to necrotizing stomatitis and noma [1]. Characteristic clinical findings define the diagnosis of NG: gingival pain; interdental necrosis, which appears as punched-out gingival papilla; and gingival bleeding [2]. Further NG-related features are foetid breath, pseudomembrane formation, and extraoral lymphadenopathy [3,4]. Originally described as necrotizing ulcerative gingivitis, the term "ulcerative" was later eliminated, because ulceration was considered to be secondary to necrosis [4].

Early findings regarding the NG-associated microbial composition of dental plaque indicated the predominance of an endogenous, opportunistic fusiforme-spirochetal infection [5-9]. However, further studies have demonstrated that NG is a more complex and variable mixed microbial infection, which does not necessarily include the predominance 
of a fusiforme-spirochetal complex as prescribed by Plaut and Vincent [2,10-12]. In the meantime, Prevotella intermedia, Selenomonas spp., and Peptostreptococcus spp. are also considered to be highly NG-related bacterial species [3]. The NG-related gingival infection can be modified by particular risk factors and interacts with a variety of host factors without a predominant periodontal pathogen $[13,14]$.

Depending on the population, the prevalence of NG varies broadly [15], although it is generally rather low $(<1 \%)$, especially in the industrialized societies of North America, Europe, and Japan. Most likely, this is due to high health standards in these countries [13]. Interestingly, the true prevalence of NG has to be further investigated due to the fact that relevant epidemiologic data were mainly obtained from non-representative population groups (low socioeconomic class [16], HIV patients [17], military officers and soldiers [18], and urban slum residents $[13,19])$ providing a probably skewed estimation.

In contrast to NG, chronic gingivitis (CG) is a widespread phenomenon, mainly in children and adolescents [20]. Although the microbial etiology of CG is proven [21,22] and similar to NG, the link to a specific individual or group of microorganisms has not been proven $[23,24]$.

According to the new classification scheme for periodontal diseases [3,25], CG is classified as a gingival disease, whereas NG constitutes a subgroup of periodontitis. Findings have concluded that CG is a reversible state and a necessary prerequisite for periodontitis, which is irreversible and more severe [26]. Therefore, patients with treated and stable periodontitis are at higher risk for recurrent periodontitis than CG patients [26]. The clinical symptoms of both diseases (CG, NG) vary broadly; the term CG describes the inflamed state of the gingiva with $>10 \%$ bleeding sites $[27,28]$, and, upon clinical examination of bleeding on probing (BOP \%), probing depths $>3 \mathrm{~mm}$ [29]. Necrotizing diseases like NG show three typical clinical features: pain, bleeding, and ulceration of the gingival interdental papilla [3]. The extent, severity, and progression of CG and NG are mainly dependent on host-related factors and systemic modifying factors $[3,26]$.

Cytokine levels in NG samples have not been investigated so far. Although there have been extensive studies on inflammation markers in CG and periodontitis in general [30], which have confirmed elevated levels of specific cytokines depending on the clinical severity of the disease, there are no literature reports describing the immunological status of NG patients [31].

Due to the fact that only limited studies have investigated samples of NG-infected patient groups so far, little is known about the microbial composition of dental plaque and expression of inflammation markers in NG. To date, some bacterial species (Porphyromonas gingivalis, Actinomyces gerencseriae, Prevotella intermedia, Prevotella nigrescens [13]) have been detected using fluorescence in situ hybridization (FISH) or immunofluorescence (IF), whereas the presence of other putatively pathogenic bacterial groups in NG (Tannerella forsythia, Porphyromonas endodontalis, phylum Bacteroidetes, families Bacteroidaceae and Prevotellaceae) has not yet been ascertained.

The objective of this study is to profile the immunologic as well as the microbial landscapes associated with NG and CG and to detect differences that might help elucidate NG- and CG-specific inflammatory and bacterial markers.

\section{Material and Methods}

The study protocol was approved by the Ethics Committee of the University of Zurich (Basec Nr. Req-2019-01260). All assay protocols and data sampling were conducted in accordance with relevant institutional and national guidelines and regulations. Thirty inflammatory proteins were tested using an ELISA assay based on blood serum samples, while marginal plaque was chosen to quantify six bacterial probes using FISH and fluorescence microscopy and to extract DNA for $16 \mathrm{~S}$ rRNA amplicon sequencing. The cohort consists of 42 individuals, $21 \mathrm{NG}$, and 21 CG patients. 


\subsection{Patients and Sample Collection}

Patient selection, clinical examination, and collection of interdental marginal plaque took place in 1998/1999 and were described previously [13,32]. In brief, upon giving their written informed consent, 42 otherwise healthy Chinese patients with either NG ( $n=21$; mean age of $36.9 \pm 6.7$ years) or CG ( $n=21,38.9 \pm 6.3$ years) formed our test groups. All NG patients had multiple typical clinical signs for NG, such as interdental necrosis, characterized by the loss of gingival papillae, pseudomembrane formation, fetid odor, gingival pain, and ulceration [2], whereas CG patients displayed strong gingival inflammation in the absence of any of the mentioned characteristic signs of NG. Marginal supragingival plaque samples were collected from the buccal and/or oral surfaces of the most disease-affected regions following a procedure previously described by the authors [13,32-37]. Sample material from three infected sites was pooled in $1 \mathrm{~mL}$ reduced transport fluid (RTF) containing 10\% glycerol [38]. Plaque samples were split into aliquots and stored in liquid nitrogen.

Peripheral blood samples were taken from the median cubital vein and the serum was stored at $-80^{\circ} \mathrm{C}$. Exclusion criteria during patient selection were (i) presence of any form of severe systemic disease or diseases of the salivary glands, (ii) dentition with less than 20 teeth, (iii) periodontal pockets with probing pocket depth $4 \mathrm{~mm}$, and (iv) use of antibiotics or local antimicrobial mouth rinses such as chlorhexidine (CHX) within the last 3 months.

\subsection{DNA Extraction}

The DNA from plaque samples (NG, CG) was isolated using the GenEluate bacterial genomic DNA kit (Sigma-Aldrich, Saint Louis, MI, USA). The manufacturer's recommendations were followed except for slight modifications to the pretreatment steps required for the lysis of Gram-positive bacteria: we extended lysis to $1 \mathrm{~h}$ using a mix of lysozyme $\left(2.115 \times 10^{6} \mathrm{U} / \mathrm{mL}\right)$, mutanolysin $(250 \mathrm{U} / \mathrm{mL})$, lysostaphin $(200 \mathrm{U} / \mathrm{mL})$ and achromopeptidase (600-1200 U/mL)) followed by treatment with proteinase $\mathrm{K}$ for $20 \mathrm{~min}$. The extracted DNA was eluted twice in $60 \mu \mathrm{l}$ preheated elution buffer. The amount of isolated DNA was determined using a NanoDrop ND-1000 spectrophotometer (Thermo Fisher Scientific, Waltham, MA, USA).

\subsection{Amplification and Illumina MiSeq High-Throughput Sequencing}

The variable regions V1-V3 of the 16S rRNA gene were amplified by PCR using primers 27F 5- GAG TTT GAT CCT GGC TCA GAT TGA ACG C-3 and 534R 5-XXXXXXXX ATT ACC GCG GCT GCT GG-3 [39]. PCR was carried out in a total volume of $50 \mu \mathrm{L}$ containing $1 \times$ NEBNext High-Fidelity PCR Mastermix (New England BioLabs), $1.25 \mu \mathrm{M}$ of each primer, and $5 \mu \mathrm{l}$ of sample DNA. PCR steps included initial denaturation at $98^{\circ} \mathrm{C}$ for $30 \mathrm{~s}$, followed by 30 cycles consisting of denaturation at $98^{\circ} \mathrm{C}$ for $10 \mathrm{~s}$, annealing at $65^{\circ} \mathrm{C}$ for $30 \mathrm{~s}$ and extension at $72{ }^{\circ} \mathrm{C}$ for $30 \mathrm{~s}$ and a final extension step at $72{ }^{\circ} \mathrm{C}$ for $5 \mathrm{~min}$. The PCR products were purified with the NucleoSpin Gel and PCR Clean-up Kit (MachereyNagel, Düren, Germany) according to the manufacturer's protocol, using a 1:4 dilution of the binding buffer NTI. The amount and the quality of the purified PCR amplicons were analyzed by a Qubit fluorometer (Invitrogen, Waltham, MA, USA,) and by agarose gel electrophoresis. For sequencing, the PCR amplicons were pooled in equimolar amounts.

The reverse primer contains inline barcodes for multiplexed sequencing. PCR products were pooled equimolar and Illumina sequencing adapters were attached using the NEB Next Ultra II Library preparation Kit (NEB, Ipswich, MA, USA). The samples were sequenced with 300 cycles paired-end on a MiSeq (600 cycles V3, Illumina, Inc, San Diego, CA, USA) and demultiplexed according to the inline barcodes.

\subsection{Analysis of the $16 S$ rRNA Data}

The fast files generated by the MiSeq were quality-filtered and adapters-trimmed using Trimmomatic v0.39 [40]. Paired-reads that passed such preprocessing steps were joined 
using fastq-join [41] and then aligned to the Silva bacterial database using minimap2 [42]. Based on the alignments, genus-level abundances were obtained by aggregating all the species with the same parent genus and compared with the FISH data. Krona plots were generated using KronaTools [43].

\subsection{Fluorescence In Situ Hybridization (FISH)}

For semi-quantitative analysis of the phylum Bacteroidetes (CFB935), the families Bacteroidaceae and Prevotellaceae (BAC303), and the genus Prevotella (PRV392), as well as the bacterial species Porphyromonas gingivalis (L-Pgin1006-2), Porphyromonas endodontalis (Pend740), and Tannerella forsythia (Tfor127), FISH was performed. In brief, the aliquots of the pooled marginal plaque samples were thawed, homogenized by the standard vortexingsonication procedure for $10 \mathrm{~s}$ at $40-50 \mathrm{~W}$ on ice (Sonifier B-12; Branson, Danburg, CT, USA). The CG and NG samples were diluted (1:50) in coating buffer $\left(0.9 \% \mathrm{NaCl}, 0.02 \% \mathrm{NaN}_{3}\right.$, $2.5 \times 10^{-4} \%$ hexadecyltrimethylammonium bromide; CTAB) [34]. Ten microliters of these suspensions were divided and fixed on 24-well epoxy-coated slides with a well diameter of $4 \mathrm{~mm}$ (Cell-Line, Erie Scientific Company, Portsmouth, NH, USA) to be used for FISH as previously described [34]. To include Gram-positive bacteria, additional permeabilization was conducted as follows: 2 min exposure to $7 \mu \mathrm{L} /$ well of lysozyme (70 $\mathrm{U} / \mu \mathrm{L})$, aspiration of lysozyme droplet, brief dipping in nanopure water $\left(\mathrm{H}_{2} \mathrm{O}\right)$ followed by air-drying [44] Blocking of unspecific binding included treatment with Denhardt's solution (Sigma-Aldrich, St. Louis, MO, USA; diluted (1:50) in $0.9 \% \mathrm{NaCl})$ in the presence of protectRNA RNase inhibitor (1:500, Sigma-Aldrich Chemie GmbH, Buchs, Switzerland) in $0.9 \% \mathrm{NaCl}$ and incubation for $30 \mathrm{~min}$ at $37^{\circ} \mathrm{C}$ [33]. Seven validated, labeled at the $5^{\prime}$ - end with Cy3 or carboxyfluorescein (FAM) (Microsynth, Balgach, Switzerland) and specific oligonucleotide rRNA-directed probes were used. The sequences of the rRNA directed probes and bacterial targets are listed in Table 1.

Table 1. Characteristics of 16S rRNA-directed oligonucleotide probes used for FISH; target organisms, rRNA sequences, target site, and formamide concentration $(\mathrm{F})$.

\begin{tabular}{|c|c|c|c|c|c|c|}
\hline Probe $^{1}$ & Target & Sequence $\left(5^{\prime}-3\right)^{2}$ & $5^{\prime}$ modification & Target Site & $F(\%)$ & Source \\
\hline BAC303 & $\begin{array}{l}\text { Most Bacteroidaceae and Prevotellaceae, } \\
\text { some Porphyromonadaceae }\end{array}$ & CCA ATG TGG GGG ACC TT & Cy3 & $303-319$ & 50 & [45] \\
\hline CFB935 & Bacteroidetes (very broad) & CCA CAT GTT CCT CCG CTT GT & Сy3 & $935-954$ & 50 & [46] \\
\hline EUB338 & $\begin{array}{l}\text { Many but not all bacteria/ } \\
\text { most eubacteria }\end{array}$ & GCT GCC TCC CGT AGG AGT & Carboxyfluorescein & $338-355$ & $40-50$ & {$[47]$} \\
\hline L-Pgin1006-2 & P. gingivalis & GTT TTC ACC ATC MGT CAT C & Су3 & $1006-1024$ & 45 & [48] \\
\hline Pend740 & $\begin{array}{c}\text { P. endodontalis } \\
\text { Prevotellaceae (Prevotella, }\end{array}$ & CAG TGT CAG ACG GAG CCT & Cy3 & $740-757$ & 40 & [49] \\
\hline PRV392 & $\begin{array}{l}\text { Hallella)/Prevotellaceae (Prevotella spp., } \\
\text { Alloprevotella spp., Hallella spp.) }\end{array}$ & GCA CGC TAC TTG GCT GG & Cy3 & 392-308 & 50 & [50] \\
\hline Tfor127 & T. forsythia & CTC TGT TGC GGG CAG GTT AC & Cy3 & $127-146$ & 40 & [33] \\
\hline
\end{tabular}

${ }^{1}$ Probes were labeled at the $5^{\prime}$-end with Cy3 (Cyanine dye 3) or carboxyfluorescein. The designations of probes containing lockednucleic-acid (LNA) substitutions start with L-. ${ }^{2}$ Characters printed in bold indicate LNA substitutions. LNA incorporated DNA probes (LNA/DNA probes) have been described to significantly improve fluorescence intensity in comparison to conventional DNA probes with the same sequence.

The universal probe EUB338 was used as a reference [47]. The final probe concentrations added to the individual wells were $5 \mathrm{ng} \mu \mathrm{L}^{-1}$ for Cy3 (Cyanine dye) and $20 \mathrm{ng} \mu \mathrm{L}^{-1}$ for FAM conjugates. Depending on the probe, $40-50 \%$ formamide as part of the hybridization buffer was used. The backbone of the hybridization process is represented by the previously described methods of Manz et al. [51] and Züger et al. [33], successively modified by Thurnheer et al. [52]. More precisely, the following alterations were made to the workflow described in [33]: (i) increased duration of hybridization (240 min), (ii) general DNA cell staining using 4',6-diamidino-2-phenylindole (DAPI) incorporated in glycerolbased mounting fluid (VECTASHIELD ${ }^{\circledR}$ Mounting Medium, Vector Laboratories Ltd., Peterborough, UK) was performed for all controls. 


\subsection{Image Acquisition and Analysis}

As described in earlier studies [44], upon FISH, the stained bacteria were visualized using an Olympus BX60 epifluorescence microscope fitted with phase-contrast (Olympus Optical AG, Volketswil, Switzerland), an HBO $103 \mathrm{~W} / 2$ mercury photo optic lamp for excitation (OSRAM Lighting AG, Winterthur/Toess, Switzerland) and Olympus filter sets U-MNIBA (FAM, FITC; excitation, 470-490 nm; emission, 515-550 nm) and U-MA41007 (Cy3; excitation, 530-560 nm; emission, 575-645 nm). Additionally, the 4',6-diamidino2-phenylindole (DAPI) filter set U-MWU (excitation, 330-385 nm; emission > $420 \mathrm{~nm}$ ) was used for DNA staining. Exposure times for Cy3 and FAM were set at $800 \mathrm{~ms}$ and $2000 \mathrm{~ms}$, respectively. Phase contrast-, colored-, and grayscale images of the FISH samples were taken as 8-bit micrographs with an Olympus DP74 camera and the cellSens Entry 1.15 Imaging Software (Olympus Optical AG, Volketswil, Switzerland). At least 10 viewing fields per well at $1000 \times$ magnification were chosen with respect to: (i) absence of artifacts or aggregates, and (ii) presence of DAPI-stained bacteria. The grayscale images were further analyzed using cellSens Dimension Desktop 1.15 Imaging Software (Olympus Optical AG, Volketswil, Switzerland). For improved detection, automatic contouring of every micrograph was conducted. The covering grades of the stained bacteria (in \%) were estimated by setting the areas of the Cy 3 colored probes (target species) and FAM colored probe (total eubacteria) in relation to each other. The density threshold of the bacterial boundary was set manually for each image and stain. To be regarded as "true signals", the objects had to be: (i) positive after using phase-contrast imaging and DAPI to avoid inclusion of possible false-positive signals, and (ii) positive for eubacteria. The areas considered to be positive for the respective probe were cross-checked by both phasecontrast- and colored images. The total area covered by the fluorescently labeled bacteria was described as an absolute value in $\mu \mathrm{m}^{2}$. The stained area with positive fluorescence signals for the EUB338 probe was taken as reference $(100 \%)$ and the covering grade of the other probes was finally measured as a percentage (\%) of the EUB338-positive areas.

\subsection{Determination of Cytokines, Chemokines, and Growth Factors}

The serum samples of the CG and NG patients were thawed and intensely vortexed for $30 \mathrm{~s}$. Subsequent centrifugation at $4{ }^{\circ} \mathrm{C}$ at $21,000 \times g$ for $5 \mathrm{~min}$ in $1.5 \mathrm{~mL}$ Protein LoBind Tubes (Eppendorf AG, Hamburg, Germany) pelleted any insoluble material [53]. The final sample of $50 \mu \mathrm{L}$ as duplicates (twice for a total of $100 \mu \mathrm{L}$ ) of clear supernatant was removed and used according to the instructions of the Human Cytokine Magnetic 30 Plex Panel (Novex, ThermoFisher Scientific, Waltham, MA, USA) [54]. This panel quantifies cytokines, chemokines, and growth factors in the collected medium [54]. Levels of the analytes in $\mathrm{pg} / \mathrm{ml}$ were detected by multiplex bead array assays (MBAA) and read by Luminex ${ }^{\circledR} 200$ (Bio-Rad Laboratories Inc., Hercules, CA, USA). Analysis of the data was conducted by polynomial interpolation in Microsoft Excel for further statistical processing.

\subsection{Statistical Analysis}

To check for statistical differences between the two clinical groups with respect to the quantitative protein assay and FISH staining, a Mann-Whitney test was employed. We used Bonferroni (in the case of the FISH assay) or Benjamini-Hochberg correction (in the case of the ELISA assay, due to the presence of protein families) to account for multiple testing. In order to compare differential abundances between the groups in the $16 \mathrm{~S}$ rRNA-based NGS data, edgeR [55] was used.

\section{Results}

\subsection{Analysis of the Bacterial Communities in the Two Cohorts: FISH}

Box plots in Figure 1 depict the relative abundance of the six hybridized oligonucleotide probes in the FISH - treated dental plaque samples from subjects with CG and NG. The corresponding targets of the probes can be seen in Supplementary Table S1; CFB935 is considered as the "Bacteroidetes" probe. 

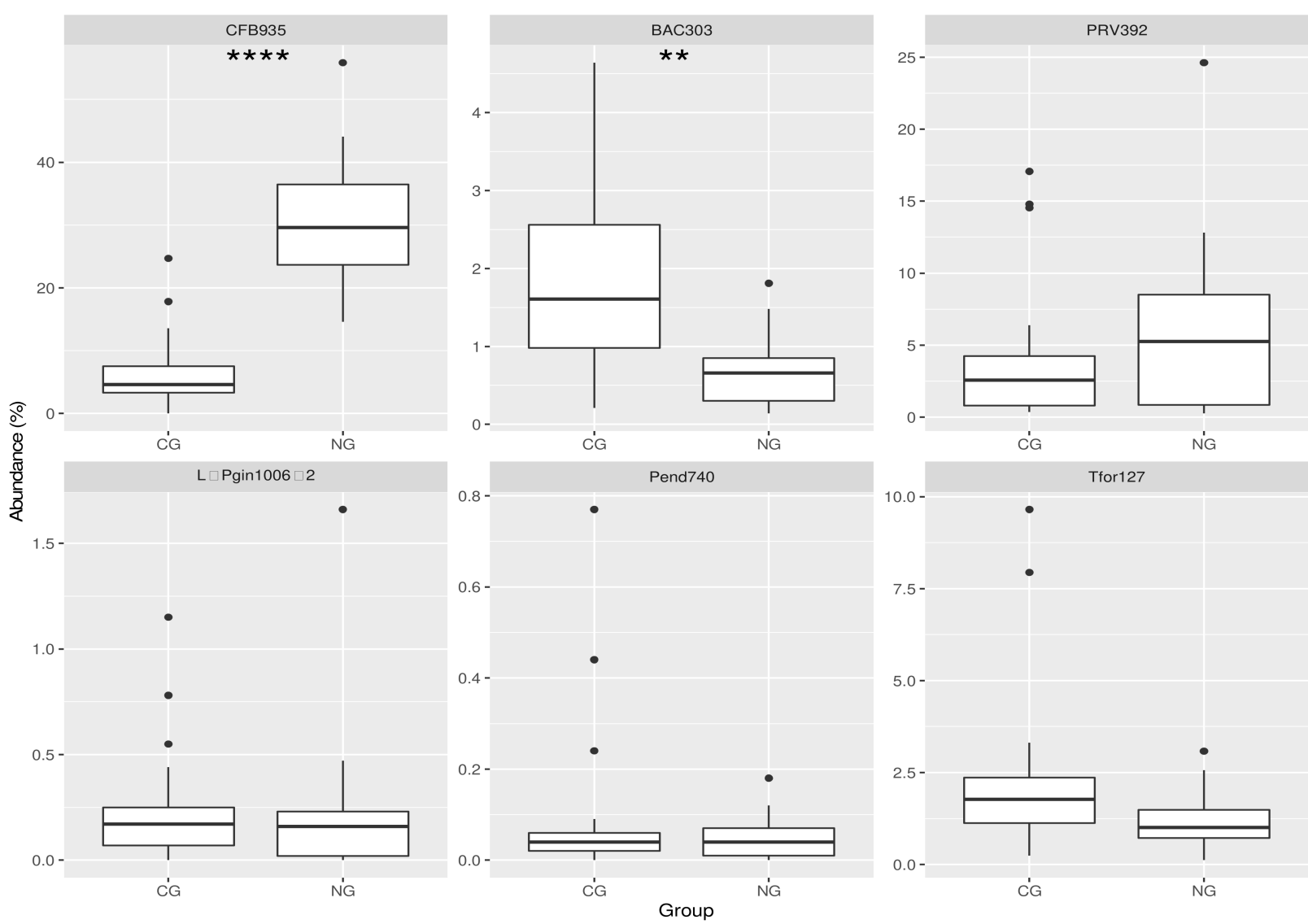

Figure 1. Box plots showing the abundance of six taxa in relation to the total amount of bacteria in samples from patients with chronic $(n=21)$ or necrotizing gingivitis $(n=21)$. Data are shown for the phylum Bacteroidetes, the families Bacteroidaceae and Prevotellaceae, the genus Prevotella and the species P. gingivalis, P. endodontalis und T. forsythia. Note that y-axis scales are different for each taxon. 16S rRNA probes used to detect the different taxa are described in Supplementary Table S1. $p$-values were calculated with the Bonferroni-corrected Mann-Whitney test; $\left.p<0.0001\left({ }^{* * *}\right), p<0.01{ }^{* *}\right)$. CG, chronic gingivitis; NG, necrotizing gingivitis. CFB935; BAC303; PRV392; L-P GIN 1006-2; Pend740; Tfor127 are probes with different targets (see Table 1).

Probe CFB935 represents, on average, the probe that, among those tested, captured the largest amount of microorganisms in both NG and CG biofilms. However, at 30.6\% and $6.7 \%$, there is a strong significant difference $(p<0.0001)$ between the two groups; in particular, the probe CFB935 was significantly more abundant in NG. Interestingly, among CG patients we identified one outlier, showing a high CFB935 abundance $(24.7 \%)$, while in the NG group, two patients presented a lower proportion of cells stained by this probe $(17.5 \%$ and $14.6 \%)$.

The other probe which shows a statistical difference in its abundance between the two groups $(p<0.01)$ is BAC303. Its fraction is much lower than CFB935, with mean values in the CG and NG groups of $1.91 \%$ and $0.70 \%$, respectively.

No significant differences were detected between CG and NG groups with respect to the cell content stained with the other four probes (Supplementary Table S2).

Supplementary Figure S1 contains representative fluorescence microscopy (FM) images of the same samples generated with FISH following hybridization with the aforementioned probes.

Fluorescence microscopy (FM) panels illustrating the presence of specific phyla, genera, and bacterial species related to necrotizing gingivitis. Images were generated with FISH and FM following hybridization with the following oligonucleotide probes: broadspectrum CFB935 staining cells of the phylum Bacteroidetes with diverse morphology (A); BAC303 staining differently sized aggregates of Bacteroides spp., Prevotella spp., and Porphyromonas spp. (B); PRV392 staining rod-shaped cells of Prevotella spp. (C); Pend740 and 
L-Pgin1006-2 staining small, round cells of P. endodontalis (D) and P. gingivalis (E), respectively. The bacterial targets are zoomed and highlighted on white-framed sub-images in panels $\mathrm{A}$ and $\mathrm{C}$.

\subsection{Analysis of the Bacterial Communities in the Two Cohorts: $16 S$ rRNA NGS Comparison with} FISH Data

In addition to using FISH probes to capture predefined organisms, we also amplified and sequenced the $16 \mathrm{~S}$ rRNA V1-V3 regions in order to screen the microbial community of the cohorts. To gauge the robustness of the NGS profiling, we first compared it with the FISH data. In Figure 2, we show the coefficients of correlation between the relative abundances calculated based on the NGS analysis and those based on the FISH staining. Of course, this is only possible for the genera (or set of genera) included in the FISH probes.

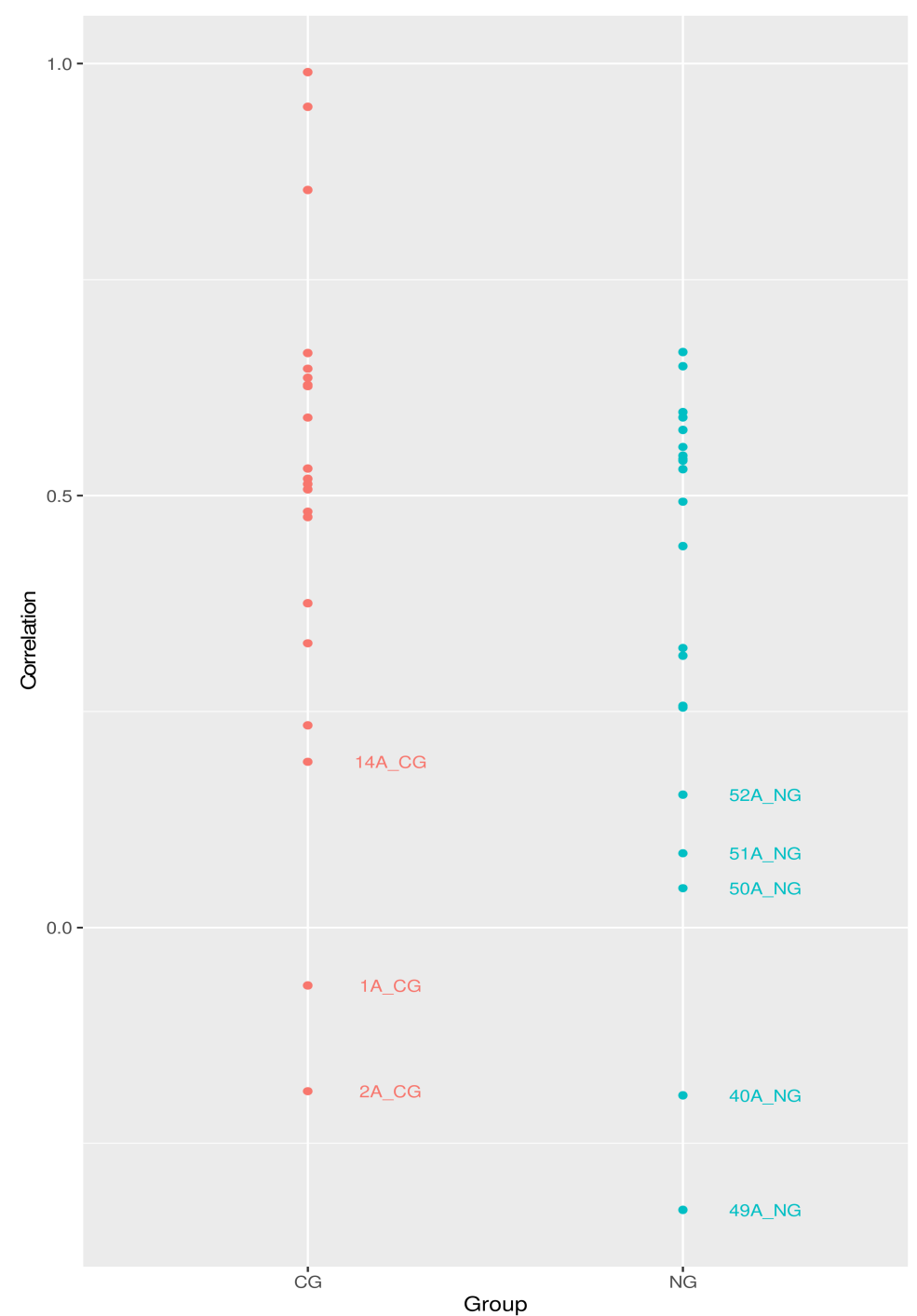

Figure 2. Correlation between the FISH-based and NGS-based relative abundances of the selected microbial species. The plotted value is the Pearson coefficient between the species quantities in each sample. Samples with $R^{2}<0.2$ are labeled.

For the majority of the samples, the level of correlations is above 0.5 and can be considered moderately strong. The samples labeled in Figure 2 have a correlation coefficient below 0.2 (very weak) and therefore we decided to remove them from further analysis of the NGS data. Additionally, samples 47A_NG, 33A_NG, and 5A_CG have also been removed from downstream analyses involving NGS-based data, because more than $50 \%$ of the species identified in the pool were not observed (zero counts). 


\subsection{Further Profiling the Microbial Communities}

A differential abundance analysis revealed 75 species as significantly different between the two groups, whose taxonomic distribution is depicted as Krona charts in Figure 3. Specifically, 58 species were significantly more abundant among CG patients, and the majority of such difference was driven by the phylum Proteobacteria, which accounted for $67 \%$ of the differentially abundant organisms, followed by Firmicutes (21\%) and Actinobacteria (9\%). Almost all of the Proteobacteria (90\%) belonged to the class Gammaproteobacteria, which also accounted for two-thirds $(60 \%)$ of the total number of differentially abundant species. Pseudomonas and Lysobacter are the most abundant genera (20\% of Gammaproteobacteria, $12 \%$ of the total number of differentially abundant species), while almost half of the Firmicutes and $10 \%$ of the total number of differentially abundant species were Streptococcus spp.

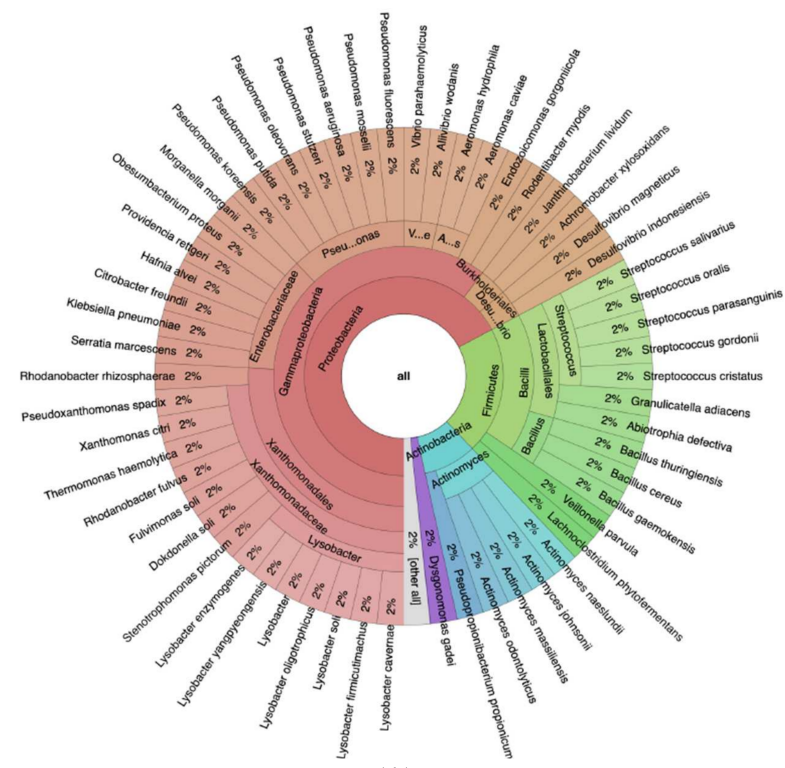

(A)

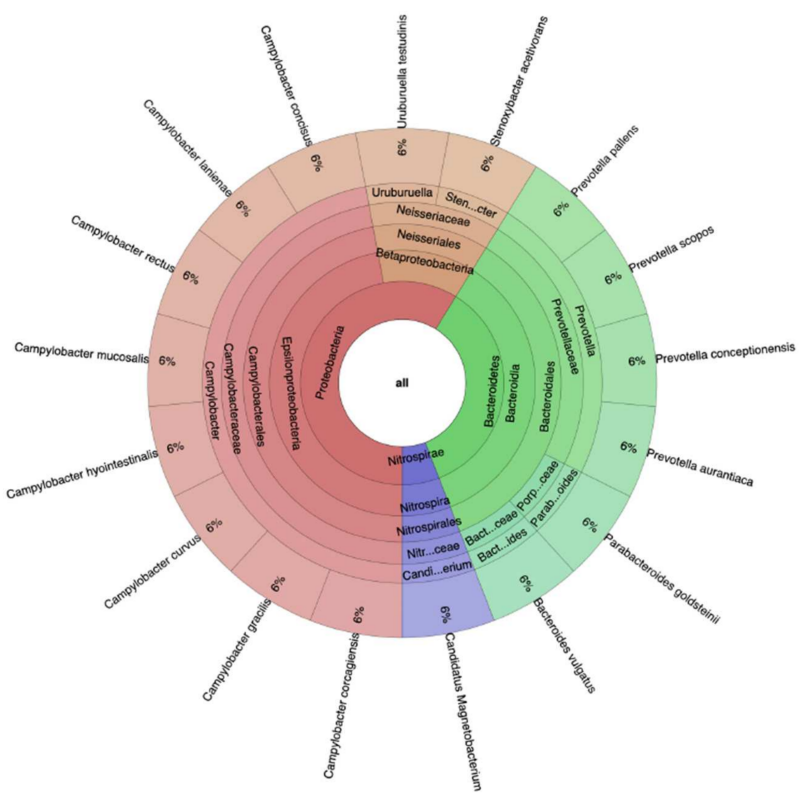

(B)

Figure 3. Krona plots of the taxonomies of the organisms which resulted in differentially abundant in the NGS analysis between the CG and NG groups. (A) Species overabundant in the CG group. (B) Species overabundant in the NG group. The full taxonomy of each species was reconstructed using the R package myTAI with the itis and NCBI databases. 
Among the 17 species which were more abundant in the NG patients, 10 (59\%) were Proteobacteria, of which 8 belonged to the Campylobacter family. The second most abundant phylum was Bacteroidetes ( 6 species, 35\%); of those, 4 belonged to the Prevotellaceae family and one to the Porphyromonadaceae. This further confirmed the results obtained by FISH analysis with respect to the probe CFB935.

A snapshot of the baseline microbial environment in the two groups is shown in Figure 4. Altogether, at the phylum level, the two groups had a very similar profile, with Proteobacteria being the most dominant phylum and representing ca. $90 \%$ of the population. However, as just discussed and shown in Figure 3, the deteriorating transition to NG was driven by a relative depletion of Firmicutes and a spike in Bacteroidetes to ca. 35\%.

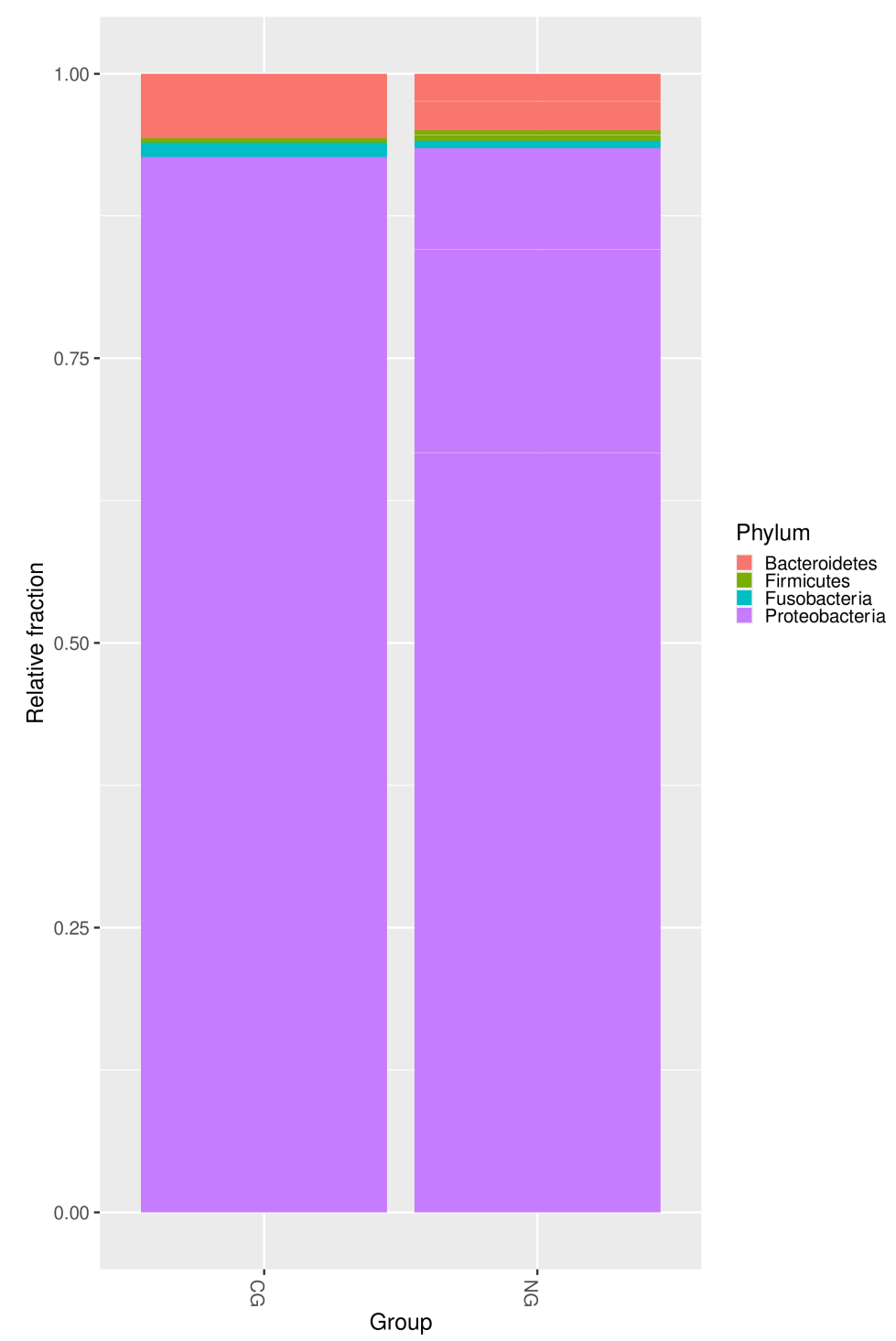

Figure 4. Relative prevalence of the ten most abundant species among the entire microbiome ("Full list"), the subset of species overabundant in the CG patients, and the subset of species overabundant in the NG.

\subsection{Analysis of the Expression of the Protein Markers}

On average, the thirty proteins tested using the 30-plex MBAA displayed pretty similar expression levels between the groups (Supplementary Figure S2), including the very high concentration levels of RANTES (ca. 20 times the sample-wise mean in both NG and CG cohorts) and IL-8 (4 and 7 times the sample-wise mean in the NG and CG cohorts, respectively). 
The heatmap shows the concentration (in pg/ml) of a total of 30 cytokines, chemokines and growth factors among chronic gingivitis and necrotizing gingivitis patients. The rows are ordered by mean concentration value stratified according to the color bar on the right.

Out of these 30 proteins, six (G-CSF, GM-CSF, HGF, IL-13, MIG, and TFN- $\alpha$ ) were differentially abundant between the two groups (Figure 5). In all cases, the significantly higher protein expression was found in the NG cohort, suggesting a stronger inflammatory response driven by NG. However, it can be seen how in three cases (GM-CSF, IL-13, and MIG) the difference was driven by a handful of outliers over a rather low background signal, and therefore conclusions around these proteins should be more cautious. Of note, the cytokine G-CSF was the inflammatory marker with the highest level of up-regulation in necrotizing gingivitis, with a Benjamini-Hochberg adjusted $p$-value $(p=0.003)$ one order of magnitude more significant than the other five significantly different markers (Figure 5).
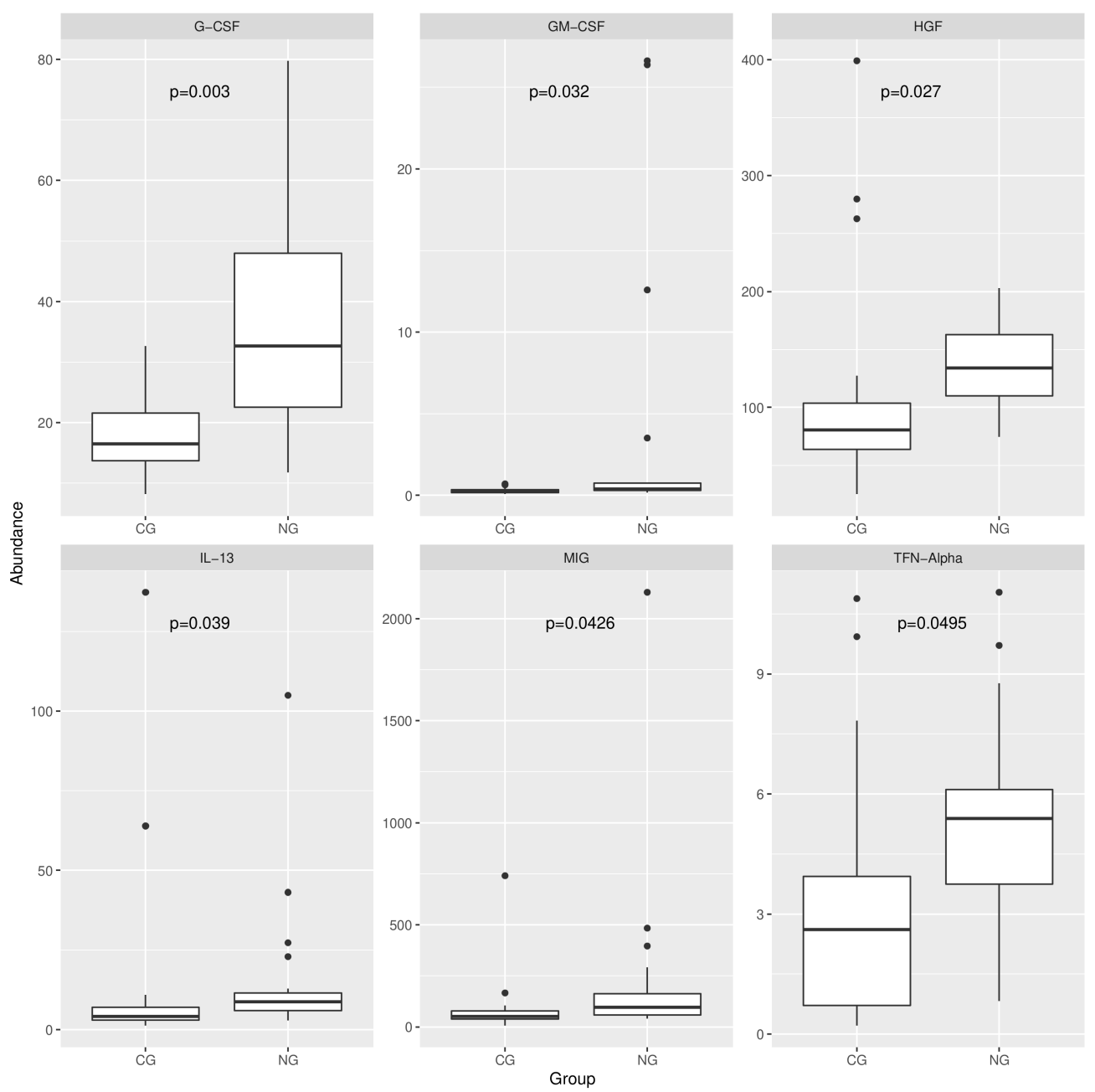

Figure 5. Box plots showing the concentration of the six proteins which are significantly differentially expressed between the NG and CG group. P-values were calculated using the Benjamini-Hochbergcorrected Mann-Whitney test.

With multiple sources of molecular information available, we also tried to investigate whether an interplay between the proteins and the microbial species associated with the diseases occurs. The three datasets (FISH, ELISA, and NGS) were integrated using the R package mixOmics with the main goal to identify co-signatures associated with multiple data sources (also called blocks in the package). As in each block, the main discriminative component was identified, and a correlation between such components was calculated for each pair of datasets. In this respect, the correlations were moderately strong for all three datasets, with the FISH and NGS blocks showing the highest correlation $(\mathrm{R}=0.69)$. 
The corresponding discriminating effect of the individual blocks is shown in Figure 6A: one notices how robust discrimination between the groups was in all three blocks, which showed little to no overlap along the $x$-axis. However, the second component correlated well only in the NGS and ELISA datasets ( $R=0.59$, Supplementary Table S3), suggesting a potential co-signature from these blocks.

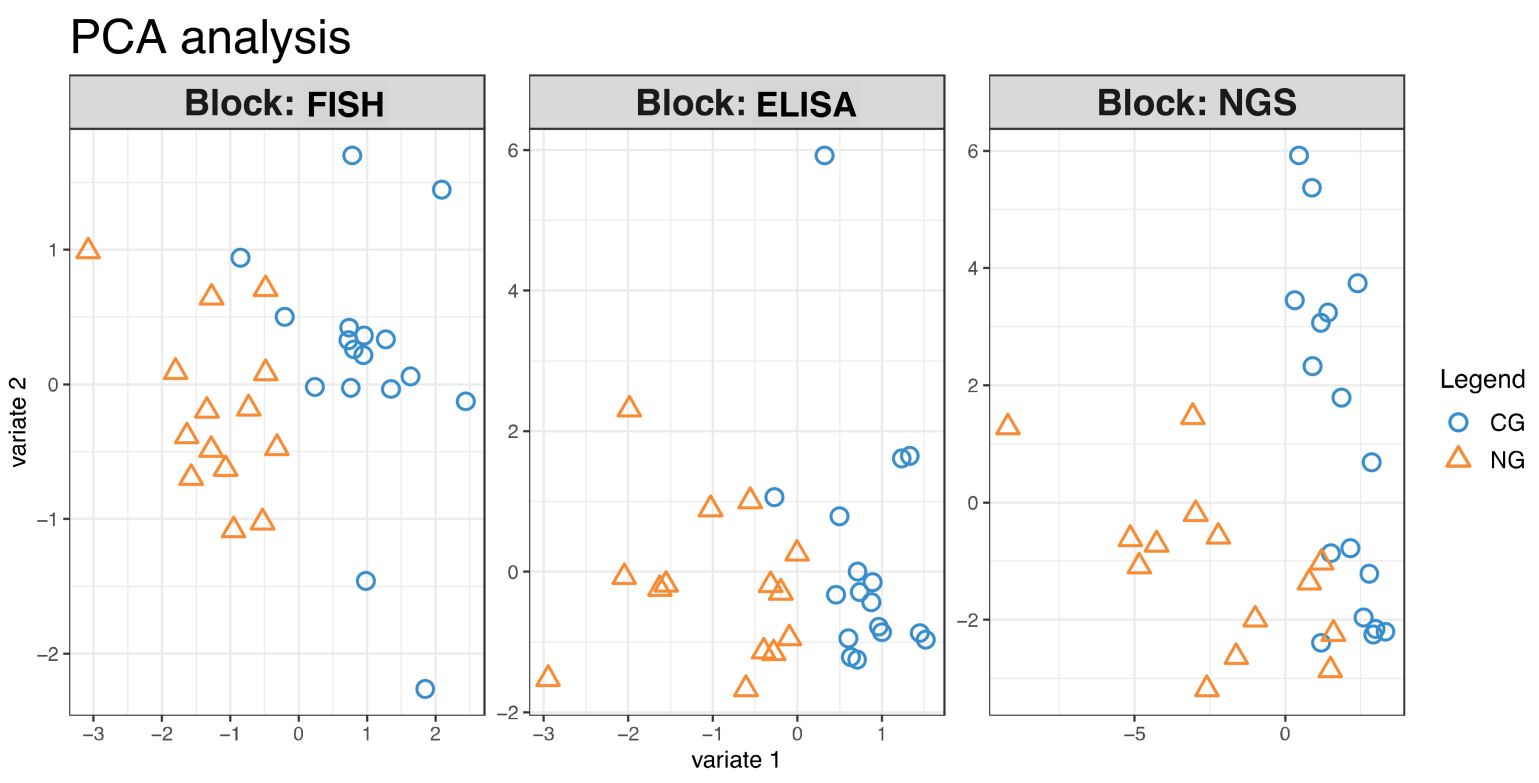

(A)

Correlation Circle Plot

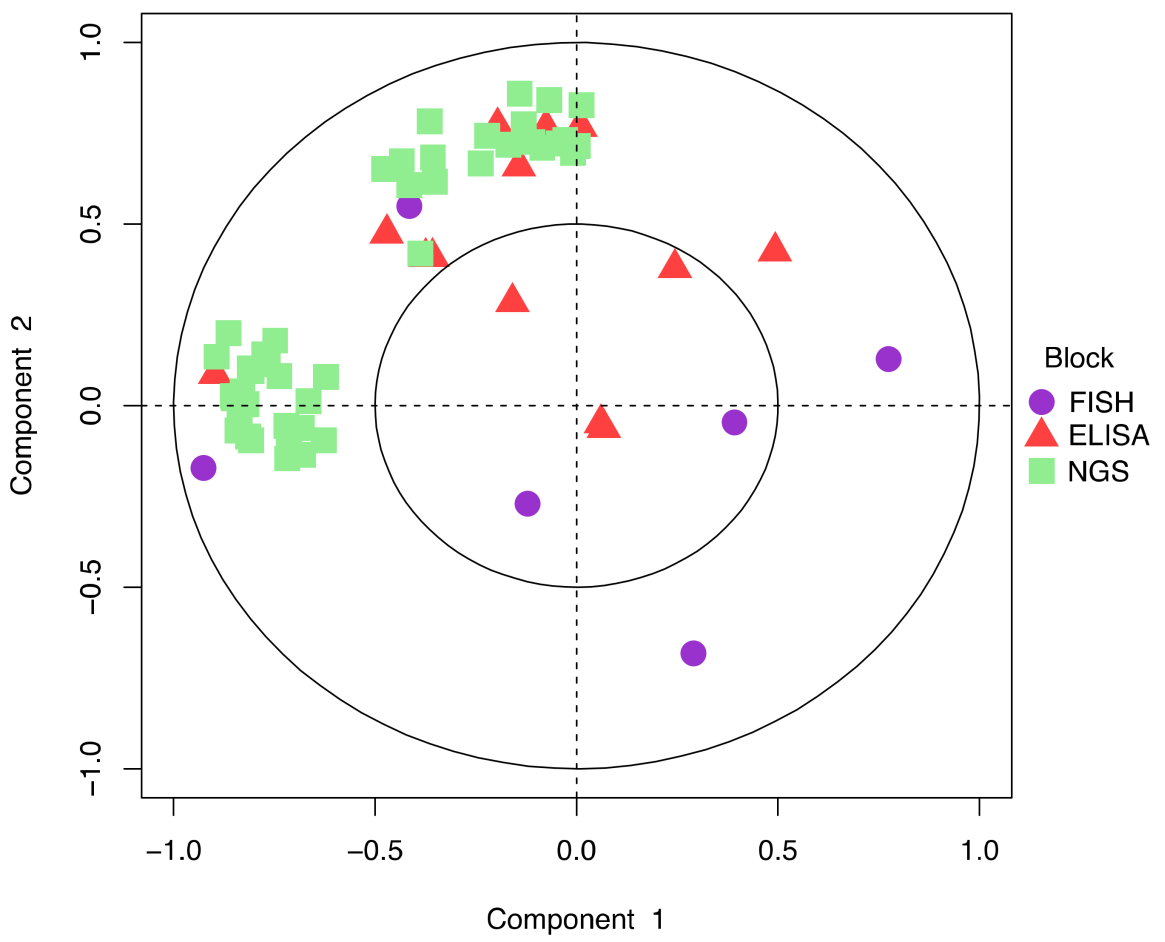

(B)

Figure 6. Cont. 


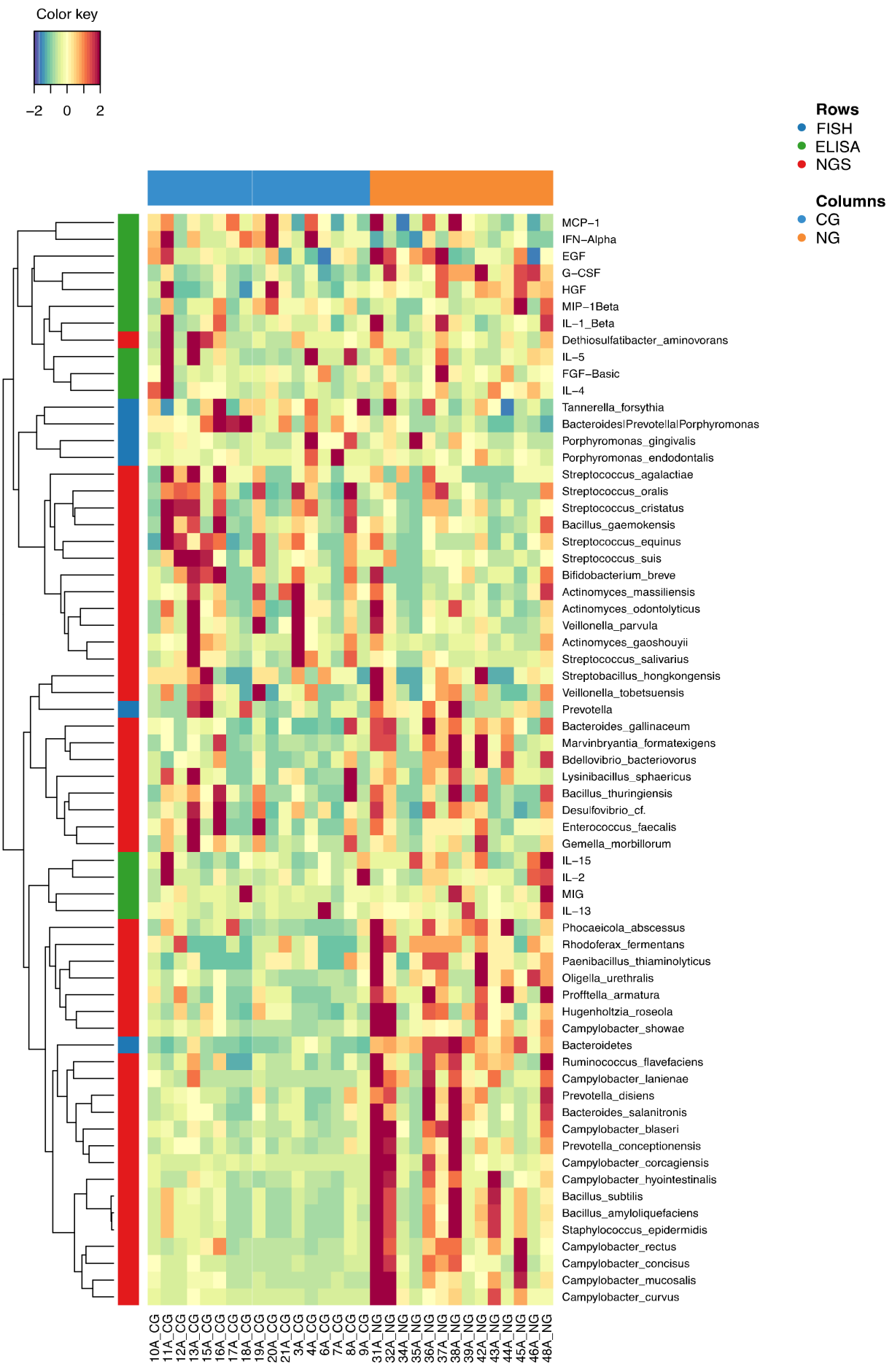

(C)

Figure 6. Integration of the three sources of data. (A) Individual principal component plots for the three blocks. Plot generated using the function plotIndiv from the package mixOmics. (B) Correlation circle plot: the further away from the origin, the higher the discriminative power of the features. Features clustering together represent potential co-signature from multiple data sources. Plot generated using the function plotVar from the package mixOmics. (C) Heatmap highlighting co-segregation of different data sources and the discriminative potential of the resulting clusters. The key color scales are based on Z-scores and scaled based on the row mean. Plot generated using the function cimDiablo from the package mixOmics.

Abundance and statistical analysis of the ELISA-based quantification for the 30 selected protein inflammatory markers. 
Additional evidence that the NGS and ELISA blocks showed an additional predictive power and an interplay between some of their features is shown in Figure 6B: the main component, along the x-axis, was polarized by a cluster of mostly NGS features, whereas the second main component, along the y-axis, was polarized by another NGS-dominated cluster also including some ELISA features. Finally, we asked ourselves which features are actually driving this behavior, and the results are shown in Figure 6C. The dendrogram clearly splits the features into two main clusters, each of which branches into two further groups. For the bottom cluster, the top branch, starting with S. hongkongensins and ending with $D$. magneticus does not show any particular trend, while the bottom branch displays an overall enrichment in the CG group and comprises several Streptococcus spp. whose spike in the CG group is already shown in Figure 4. The top cluster is instead picking up the up-regulation in the NG group; the top branch includes the proteins (including two of the three-G-CSF, HGF- which were found differentially abundant by means of the ELISA assay). The bottom branch includes the NGS-identified species, clearly showing the many Campylobacter spp. which are overabundant in the NG group and essentially replicating the results observed by analyzing the NGS dataset alone in the classical way (Figure 3B). Such sub-clustering of protein and microbial features is another way to depict the interplay seen in the y-axis cluster in Figure 6B.

\section{Discussion}

The present study confirmed the assumption that NG is an opportunistic, mixed microbial infection. The FISH-stained microscopic images demonstrated the increased occurrence of the phylum Bacteroidetes, while the genera Porphyromonas spp. and Tanerella spp. showed an increase among NG patients (CFB935 probe). Several studies from our own group have so far focused on NG [13,32-37,56], revealing the prevalence of Actinomyces gerencseriae, Campylobacter rectus, Fusobacterium nucleatum/Fusobacterium periodonticum, Porphyromonas gingivalis, Prevotella intermedia / Prevotella nigrescens, and Tannerella forsythia after FISH-staining and subsequent FM $[13,33,34,44,52,57]$. The protein quantification revealed an increased expression of inflammatory markers in NG contrary to CG.

Plaque harboring highly diverse bacteria and the presence of the above-mentioned bacterial species has been proved by other $16 \mathrm{~S}$ rRNA studies [58]. The $16 \mathrm{~S}$ rRNA gene-based analysis is an effective method for the characterization of the oral microbiota [59]. The significantly higher prevalence of CFB935-stained oral genera in NG compared to CG patients confirmed the understanding of NG as a mixed microbial infection rather than a disease with abundant fusiform-spirochete bacterial flora [60]. The probe CFB935 described as Cytophaga-Flexibacter-Bacteroides assemblage contains among other species the putative periodontal pathogens P. gingivalis, P. intermedia, P. endodontalis, and T. forsythia $[13,34,49,61,62]$. In our study, about $30 \%$ of the bacteria stained with the EUB338 probe consisted of the aforementioned bacteria. The EUB338 probe detects most of the domain Bacteria except for target organisms of the phyla Planctomycetales and Verrucomicrobia [63]. These specific bacterial species may display an "inflammophilic" profile and can support the occurrence and progression of NG in the presence of a weak immune response [62]. However, the high incidence of Bacteroidetes in NG in contrast to CG may be attributed to the fact that the bacterial genome sequence data contain only part of the sequences of oral bacteria.

The high prevalence of $P$. gingivalis among NG patients $(0.7 \%)$ versus CG patients $(0.1 \%)$ was highlighted by Gmür et al. [13]. The results of the present study, which showed no significant differences in $P$. gingivalis between NG $(0.2 \%)$ and CG $(0.2 \%)$ samples, suggest that further studies on single bacterial species will be required in order to detect differences in the bacterial composition between NG and CG patients. A possible explanation for the non-significance could be the expression of different subtypes of fimA genotypes [64,65]. Additionally, it is possible that aggregates of diverse Porphyromonas are not appropriately represented in the image acquisition.

To have an overview of the microbial populations in the oral cavities of the patients, we amplified the $16 \mathrm{~S}$ rRNA region from the DNA and performed high-throughput sequencing. 
On the one hand, the previously reported roles of individual species in the progression of NG was confirmed and expanded to close relatives, as in the case of Campylobacter and Prevotella spp. Both genera are known to be associated with periodontal disease [66] and our findings might point to their stronger involvement in the more advanced forms of pathologies such as NG. On the other hand, Lysobacter spp. and Streptococcus spp. were significantly upregulated in the CG samples. As Lysobacter spp. and Streptococcus spp. populate the oral cavity in normal conditions, and since gingivitis represents an early stage, less inflammatory form of periodontitis, it is likely that what we are observing is a displacement of some of these more common, generally innocuous species by their more pathogenic and inflammatory counterparts.

The immune response of a patient is modulated by proteins such as chemokines (chemotactic cytokines), cytokines, and growth factors [67-70], whose complex interaction leads to a vicious cycle with cumulation in tissue destruction and disease progression. The MBAA revealed that NG elicited the strong response of three serum cytokines (GCSF, TNF- $\alpha$, and HGF) and an additional, albeit less conclusive, upregulation of further three cytokines (GM-CSF, IL-13, and MIG).

The NG is a severe chronic inflammation characterized by an elevated granulocyte activity and thus, an increase in the number of blood neutrophils. Colony-stimulating factors (CSF) constitute a group of four different cytokines (granulocyte-macrophage colonystimulating factor (GM-CSF), macrophage colony-stimulating factor (M-CSF), granulocyte colony-stimulating factor (G-CSF) and multi-CSF (interleukin [IL-3]) [71]. They are produced by activated leukocytes and stimulate the proliferation, differentiation, maturation, and survival of granulocytes and macrophages. These cytokines play a myriad of roles in inflammation as pro-inflammatory cytokines [72-74]. The cytokine G-CSF regulates granulopoiesis, serves as a key mediator of the stress granulopoiesis response [75], and also affects neutrophil phenotype and function [76]. The G-CSF concentration increases in the serum at inflammatory sites [77,78]. Beneath its function as a CSF [75], GM-CSF affects and modulates more myeloid cell types, especially macrophages, granulocytes and eosinophils [79]. Expression of GM-CSF is normal under homeostatic conditions but increased under inflammatory conditions [80] as confirmed by the findings of this study.

Hamilton et al. [72] described a pro-inflammatory 'CSF network' of mutual dependence between CSF activity and the activity of monocyte- or macrophage-derived proinflammatory cytokines (such as IL-1 and TNF) [81].

In oral epithelial cells, IL-1b and TNF-alpha induce COX-2 leading to increased prostaglandin E2 production in HGFs [82,83]. In their study, Noguchi et al. [84] observed that high prostaglandin concentrations resulted in increased cytokine secretion, mainly due to positive feedback loops which contribute to the exacerbation of inflammation. In another report, De Oliveira et al. [85] stated that TNF-alpha plays a crucial role in the innate response against the periodontopathogenic bacteria. Interestingly, high levels of TNF-a, which activates pathways that culminate in the destruction of periodontal connective tissue and alveolar bone resorption [86,87], were detected in diseased sites of individuals with severe periodontitis [88].

The hepatocyte growth factor (HGF) is produced by fibroblasts from human gingiva by IL-1, TNF-alpha, and by prostaglandin E2 $[89,90]$. Other than that, it can be induced in culture by fimbriae of $P$. gingivalis [91] as well as $P$. intermedia [92]. This cytokine promotes the progression of periodontitis, by stimulating intense growth of epithelial cells and preventing regeneration of connective tissue attachments [93]. Increased levels of HGF in NG patients underline the pathogenic effects of HGF as a clinical parameter of disease progression [94].

IL-13 is a Th2 anti-inflammatory cytokine that regulates the collagen homeostasis by up-regulation of TGF- $\beta$ [95] and down-regulation of collagen-destroying MMP- 1 production [96]. Elevated levels of IL-13 have been detected in T-cells of severe periodontitis patients [97]. More recent research attributes IL-13 a pivotal role in the regulation of 
type 2 cytokine-mediated immune responses as a key inducer of many pathological processes [98].

The chemokine MIG (monokine induced by interferon (IFN)- $\gamma$ ) is stimulated by increasing production of IFN- $\gamma$ and TNF-a from recruited Th1 lymphocytes, leading to a positive amplification feedback loop in inflammatory lesions $[99,100]$. MIG is considered as a marker of the host immune response due to its T-cell chemoattractant effect, has a central function in the recruitment of inflammatory cells [99,101], and is up-regulated by RANKL in osteoclast precursor cells [102]. The findings in our study are in agreement with past studies, which showed increased serum levels of MIG in different organs in autoimmune diseases [103].

The integration of the different data sources ties together the observations discussed so far at the microbial and protein levels. All significant inflammatory activities identified by the ELISA assay represent, together with the species highly abundant in the NG samples, a co-signature for the NG. In particular, a broader inflammatory response involving, together with the significantly overexpressed HGF and G-CSF clearly indicates that the shift in the microbial composition of the plaque associated with the transition from the milder CG to the more serious NG plays a relevant role, particularly via the Campylobacter spp., in the evolution of the most severe symptoms of the disease.

\section{Conclusions}

To the best of our knowledge, this study is the first attempt to detect inflammation markers in NG patients and to integrate the microbial and inflammatory landscapes of the disease. This allowed a better understanding of the complexity of the necrotizing disease in the context of cytokine production and pointed to the potential role of specific microorganisms in the orchestration of such inflammatory response.

In conclusion, this study indicates that NG is an opportunistic, mixed microbial infection with elevated cytokine levels in the serum. Our results suggest an association between specific microbial sub-ecosystems and elevated pro-inflammatory proteins in the blood serum. It is hard to gauge to what extent this represents a causal relationship. However, our findings further reinforce the theory of dysbiosis, i.e., that neither a specific periodontal pathogen nor cytokine is responsible for the disease, but the synergistic interaction of the microbial composition in combination with a diminished host response [62].

Patients undergoing preimplant surgical procedures are prone to contamination which can lead to perimplantitis $[104,105]$. Minimally invasive tools, such as digital dentistry can help to avoid microbial infections. Other approaches involve the use of implants with reduced bacterial leakage and emerging stem cell therapy $[106,107]$.

Additional approaches, such as proteomic analysis, might help to further elucidate the molecular mechanisms underpinning the deteriorating pattern of periodontal diseases.

Supplementary Materials: The following are available online at https: / www.mdpi.com/article / 10.3390/antibiotics10101197/s1, Figure S1: Fluorescence microscopy (FM) panels illustrating the presence of specific phyla, genera and bacterial species related with necrotizing gingivitis. Images were generated with FISH and FM following hybridization with the following oligonucleotide probes: broad - spectrum CFB935 staining cells of the phylum Bacteroidetes with diverse morphology (A); BAC303 staining differently sized aggregates of Bacteroides spp., Prevotella spp., and Porphyromonas spp. (B); PRV392 staining rod - shaped cells of Prevotella spp. (C); Pend740 and L-Pgin1006-2 staining small, round cells of P. endodontalis (D) and P. gingivalis (E), respectively. The bacterial targets are zoomed and highlighted on white - framed subimages in panels A and C. Figure S2: Heatmap showing the concentration (in pg/mL) of a total of 30 cytokines, chemokines and growth factors among chronic gingivitis and necrotizing gingivitis patients. The rows are ordered by mean concentration value stratified according to the color bar on the right. Table S1: Characteristics of 16S rRNA-directed oligonucleotide probes used for FISH; target organisms, rRNA sequences, target site and formamide concentration (F).Table S2: Abundance and statistical analysis of the FISH-based quantification for the six selected bacterial probes. Table S3: Abundance and statistical analysis of the ELISA-based quantification for the thirty selected protein inflammatory markers. 
Author Contributions: Conceptualization: L.K.; Data acquisition, T.T., S.K., and G.R.; Formal analysis, N.G., T.T., R.D.G., and G.R.; Investigation, N.G.; Methodology, S.K., R.D.G. and G.R.; Project administration, T.A., and L.K.; Resources, T.A.; Software, G.R.; Supervision, T.A., and L.K.; Validation, S.K.; Visualization, R.D.G., and NG; Writing-original draft, N.G.; Writing-review \& editing, R.D.G., T.A., T.T., G.R., and L.K.. All authors have read and agreed to the published version of the manuscript.

Funding: This research was supported by institutional funds from the University of Zurich.

Institutional Review Board Statement: The study protocol was approved by the Ethics Committee of the University of Zurich (Basec Nr. Req-2019-01260). All assay protocols and data sampling were conducted in accordance with relevant institutional and national guidelines and regulations.

Data Availability Statement: Reads pre-processing: The following string was specifically parsed to Trimmomatic: ILLUMINACLIP:adapters.fa:1:30:10 LEADING:5 TRAILING:5 SLIDINGWINDOW:5:15 AVGQUAL:30 HEADCROP:0 MINLEN:180; Reads alignment: The specific database used is from Silva v 138 and can be downloaded at https:/ /zenodo.org/record/3986799\#.X9j_bulKhTY, accessed on 14 August 2021), file silva_species_assignment_v138.fa.gz. Minimap was run with the following options: $-k 27-p 0.5-N 30-x$ sr. Krona Plots: Krona was run using the tool ktImportText on ad hoc formatted abundance files. Those were created by reconstructing the taxonomy of each species through the function taxonomy() from the R package myTAI.

Acknowledgments: We thank Helga Lüthi-Schaller, Manuela Flury, and Joël Jenzer for their excellent technical support during the assays. We also thank Daniel Wiedemeier for his assistance in the statistical analysis of the results.

Conflicts of Interest: The authors declare no conflict of interest.

\section{References}

1. Herrera, D.; Alonso, B.; De Arriba, L.; Cruz, I.S.; Serrano, C.; Sanz, M. Acute Periodontal Lesions. Periodontol. 2000 2014, 65, 149-177. [CrossRef]

2. Rowland, R.W. Necrotizing Ulcerative Gingivitis. Ann. Periodontol. 1999, 4, 65-73. [CrossRef]

3. Herrera, D.; Retamal-Valdes, B.; Alonso, B.; Feres, M. Acute Periodontal Lesions (Periodontal Abscesses and Necrotizing Periodontal Diseases) and Endo-Periodontal Lesions. J. Clin. Periodontol. 2018, 45, S78-S94. [CrossRef]

4. Shangase, L.; Feller, L.; Blignaut, E. Necrotising Ulcerative Gingivitis/Periodontitis as Indicators of HIV-Infection. J. S. Afr. Dent. Assoc. 2004, 59, 105-108.

5. Smitt, P.A. Some Clinical and Epidemiological Aspects of Vincent's Gingivitis. Dent. Pract. Dent. Rec. 1965, 15, 281-286. [PubMed]

6. Hartnett, C.A.; Shiloah, J. The Treatment of Acute Necrotizing Ulcerative Gingivitis. Quintessence Int. 1991, 22, 95-100. [PubMed]

7. Courtois, G.J., 3rd; Cobb, C.M.; Killoy, W.J. Acute Necrotizing Ulcerative Gingivitis. A Transmission Electron Microscope Study. J. Periodontol. 1983, 54, 671-679. [CrossRef] [PubMed]

8. Falkler, W.A.; Martin, S.A.; Vincent, J.W.; Tall, B.; Nauman, R.K.; Suzuki, J.B. A Clinical, Demographic and Microbiologic Study of ANUG Patients in an Urban Dental School. J. Clin. Periodontol. 1987, 14, 307-314. [CrossRef]

9. Listgarten, M.A. Electron Microscopic Observations on the Bacterial Flora of Acute Necrotizing Ulcerative Gingivitis. J. Periodontol. 1965, 36, 328-339. [CrossRef]

10. Plaut, H. Studien zur Bakteriellen Diagnostik der Diphtherie und der Anginen.4. DMW-Dtsch. Med. Wochenschr. 1894, 20, 920-923. [CrossRef]

11. Vincent, M. Recherches Bacteriologiques sur l'Angine a Bacilles Fusiformes. Ann. Inst. Pasteur. 1899, $13,609$.

12. Vincent, H. Sur l'Étiologie et sur les Lésions Anatomo-Pathologiques de la Pourriture d'Hôpital. Ann. Inst. Pasteur. 1896, 10, 488.

13. Gmür, R.; Wyss, C.; Xue, Y.; Thurnheer, T.; Guggenheim, B. Gingival Crevice Microbiota from Chinese Patients with Gingivitis or Necrotizing Ulcerative Gingivitis. Eur. J. Oral Sci. 2004, 112, 33-41. [CrossRef]

14. Ranney, R.R. Classification of Periodontal Diseases. Periodontol. 2000 1993, 2, 13-25. [CrossRef]

15. Dufty, J.; Gkranias, N.; Donos, N. Necrotising Ulcerative Gingivitis: A Literature Review. Oral Health Prev. Dent. 2017, 15, 321-327.

16. Jiménez, L.M.; Duque, F.L.; Baer, P.N.; Jiménez, S.B. Necrotizing Ulcerative Periodontal Diseases in Children and Young Adults in Medellin, Colombia, 1965-2000. J. Int. Acad. Periodontol. 2005, 7, 55-63.

17. Cobb, C.M.; Ferguson, B.L.; Keselyak, N.T.; Holt, L.A.; MacNeill, S.R.; Rapley, J.W. A TEM/SEM Study of the Microbial Plaque Overlying the Necrotic Gingival Papillae of HIV-Seropositive, Necrotizing Ulcerative Periodontitis. J. Periodontal Res. 2003, 38 , 147-155. [CrossRef]

18. Horning, G.M.; Hatch, C.L.; Lutskus, J. The Prevalence of Periodontitis in a Military Treatment Population. J. Am. Dent. Assoc. 1990, 121, 616-622. [CrossRef]

19. Melnick, S.L.; Roseman, J.M.; Engel, D.; Cogen, R.B. Epidemiology of Acute Necrotizing Ulcerative Gingivitis. Epidemiol. Rev. 1988, 10, 191-211. [CrossRef]

20. Dibart, S. Children, Adolescents and Periodontal Diseases. J. Dent. 1997, 25, 79-89. [CrossRef] 
21. Löe, H.; Theilade, E.; Jensen, S.B. Experimental Gingivitis in Man. J. Periodontol. 1965, 36, 177-187. [CrossRef]

22. Theilade, E, The Experimental Gingivitis Studies: The Microbiological Perspective. J. Dent. Res. 1996, 75, 1434-1438. [CrossRef]

23. Ranney, R.R. Discussion: Pathogenesis of Gingivitis. J. Clin. Periodontol. 1986, 13, 356-359. [CrossRef]

24. Moore, L.V.; Moore, W.E.; Cato, E.P.; Smibert, R.M.; Burmeister, J.A.; Best, A.M.; Ranney, R.R. Bacteriology of Human Gingivitis. J. Dent. Res. 1987, 66, 989-995. [CrossRef]

25. Caton, J.G.; Armitage, G.; Berglundh, T.; Chapple, I.L.; Jepsen, S.; Kornman, K.S.; Mealey, B.L.; Papapanou, P.N.; Sanz, M.; Tonetti, M.S. A New Classification Scheme for Periodontal and Peri-implant Diseases and Conditions-Introduction and Key Changes from the 1999 Classification. J. Clin. Periodontol. 2018, 45 (Suppl. 20), S1-S8. [CrossRef]

26. Chapple, I.L.C.; Mealey, B.L.; Van Dyke, T.E.; Bartold, P.M.; Dommisch, H.; Eickholz, P.; Geisinger, M.L.; Genco, R.J.; Glogauer, M.; Goldstein, M.; et al. Periodontal Health and Gingival Diseases and Conditions on an Intact and a Reduced Periodontium: Consensus Report of Workgroup 1 of the 2017 World Workshop on the Classification of Periodontal and Peri-Implant Diseases and Conditions. J. Periodontol. 2018, 89 (Suppl. 1), S74-S84. [CrossRef]

27. Trombelli, L.; Farina, R.; Silva, C.; Tatakis, D.N. Plaque-Induced Gingivitis: Case Definition and Diagnostic Considerations. J. Periodontol. 2018, 89 (Suppl. 1), S46-S73. [CrossRef]

28. Ramseier, C.A.; Mirra, D.; Schütz, C.; Sculean, A.; Lang, N.P.; Walter, C.; Salvi, G.E. Bleeding on Probing as it Relates to Smoking Status in Patients Enrolled in Supportive Periodontal Therapy for at Least 5 Years. J. Clin. Periodontol. 2015, 42, 150-159. [CrossRef]

29. Ainamo, J.; Bay, I. Problems and Proposals for Recording Gingivitis and Plaque. Int. Dent. J. 1975, 25, $229-235$.

30. Khocht, A.; Rogers, T.; Janal, M.; Brown, M. Gingival Fluid Inflammatory Biomarkers and Hypertension in African Americans. JDR Clin. Transl. Res. 2017, 2, 269-277. [CrossRef]

31. Bostanci, N.; Belibasakis, G.N. Gingival Crevicular Fluid and its Immune Mediators in the Proteomic Era. Periodontol. 2000 2018, 76, 68-84. [CrossRef] [PubMed]

32. Gmür, R.; Munson, M.A.; Wade, W.G. Genotypic and Phenotypic Characterization of Fusobacteria from Chinese and European Patients with Inflammatory Periodontal Diseases. Syst. Appl. Microbiol. 2006, 29, 120-130. [CrossRef] [PubMed]

33. Züger, J.; Lüthi-Schaller, H.; Gmür, R. Uncultivated Tannerella BU045 and BU063 are Slim Segmented Filamentous Rods of High Prevalence but Low Abundance in Inflammatory Disease-Associated Dental Plaques. Microbiology 2007, 153, $3809-3816$. [CrossRef] [PubMed]

34. Baumgartner, A.; Thurnheer, T.; Lüthi-Schaller, H.; Gmür, R.; Belibasakis, G.N. The Phylum Synergistetes in Gingivitis and Necrotizing Ulcerative Gingivitis. J. Med. Microbiol. 2012, 61, 1600-1609. [CrossRef]

35. Wyss, C.; Moter, A.; Choi, B.K.; Dewhirst, F.E.; Xue, Y.; Schüpbach, P.; Göbel, U.B.; Paster, B.J.; Guggenheim, B. Treponema putidum sp. nov., a Medium-sized Proteolytic Spirochaete Isolated from Lesions of Human Periodontitis and Acute Necrotizing Ulcerative Gingivitis. Int. J. Syst. Evol. Microbiol. 2004, 54, 1117-1122. [CrossRef]

36. Wyss, C.; Dewhirst, F.E.; Gmür, R.; Thurnheer, T.; Xue, Y.; Schüpbach, P.; Guggenheim, B.; Paster, B.J. Treponema parvum sp. nov., a Small, Glucoronic or Galacturonic Acid-Dependent Oral Spirochaete from Lesions of Human Periodontitis and Acute Necrotizing Ulcerative Gingivitis. Int. J. Syst. Evol. Microbiol. 2001, 5, 955-962. [CrossRef]

37. Zinkernagel, A.S.; Gmür, R.; Fenner, L.; Schaffner, A.; Schoedon, G.; Schneemann, M. Marginal and Subgingival Plaque-A Natural Habitat of Tropheryma whipplei? Infection 2003, 31, 86-91. [CrossRef]

38. Loesche, W.J.; Hockett, R.N.; Syed, S.A. The Predominant Cultivable Flora of Tooth Surface Plaque Removed from Institutionalized Subjects. Arch. Oral Biol. 1972, 17, 1311-1325. [CrossRef]

39. Heuer, H.; Krsek, M.; Baker, P.; Smalla, K.; Wellington, E.M. Analysis of Actinomycete Communities by Specific Amplification of Genes Encoding 16S rRNA and Gel-Electrophoretic Separation in Denaturing Gradients. Appl. Environ. Microbiol. 1997, 63, 3233-3241. [CrossRef]

40. Bolger, A.M. Trimmomatic: A Flexible Trimmer for Illumina Sequence Data. Bioinformatics 2014, 30, 2114-2120. [CrossRef]

41. Aronesty, E. Comparison of Sequencing Utility Programs. Open Bioinform. J. 2013, 7, 1-8. [CrossRef]

42. Li, H. Minimap2: Pairwise Alignment for Nucleotide Sequences. Bioinformatics 2018, 34, 3094-3100. [CrossRef]

43. Ondov, B.D.; Bergman, N.H.; Phillippy, A.M. Interactive Metagenomic Visualization in a Web Browser. BMC Bioinform. 2011, 12, 385. [CrossRef]

44. Gmür, R.; Lüthi-Schaller, H. A Combined Immunofluorescence and Fluorescent in Situ Hybridization Assay for Single Cell Analyses of Dental Plaque Microorganisms. J. Microbiol. Methods 2007, 69, 402-405. [CrossRef]

45. Manz, W.; Amann, R.; Ludwig, W.; Vancanneyt, M.; Schleifer, K.H. Application of a Suite of 16S rRNA-Specific Oligonucleotide Probes Designed to Investigate Bacteria of the Phylum Cytophaga-Flavobacter-Bacteroides in the Natural Environment. Microbiology 1996, 142, 1097-1106. [CrossRef]

46. Shirazi-Beechey, S.P.; Daly, K. Design and Evaluation of Group-Specific Oligonucleotide Probes for Quantitative Analysis of Intestinal Ecosystems: Their Application to Assessment of Equine Colonic Microflora. FEMS Microbiol. Ecol. 2003, 44, $243-252$.

47. Amann, R.I.; Binder, B.J.; Olson, R.J.; Chisholm, S.W.; Devereux, R.; Stahl, D.A. Combination of 16S rRNA-Targeted Oligonucleotide Probes with Flow Cytometry for Analyzing Mixed Microbial Populations. Appl. Environ. Microbiol. 1990, 56, $1919-1925$. [CrossRef]

48. Guggenheim, B.; Gmür, R.; Galicia, J.C.; Stathopoulou, P.G.; Benakanakere, M.R.; Meier, A.; Thurnheer, T.; Kinane, D.F. In Vitro Modeling of Host-Parasite Interactions: The 'Subgingival' Biofilm Challenge of Primary Human Epithelial Cells. BMC Microbiol. 2009, 9, 280. [CrossRef] 
49. Lüdin, N.D. Phylogenetic Characterization of Subgingival Plaque Associated with Aggressive or Chronic Periodontitis. M.D. Dissertation, University of Zurich, Zürich, Switzerland, 2011.

50. Diaz, P.I.; Chalmers, N.I.; Rickard, A.H.; Kong, C.; Milburn, C.L.; Palmer, R.J.; Kolenbrander, P.E. Molecular Characterization of Subject-Specific Oral Microflora During Initial Colonization of Enamel. Appl. Environ. Microbiol. 2006, 72, 2837-2848. [CrossRef]

51. Manz, W. In Situ Analysis of Microbial Biofilms by rRNA-Targeted Oligonucleotide Probing. In Methods in Enzymology; Academic Press: Cambridge, MA, USA, 1999; pp. 79-91.

52. Thurnheer, T.; Gmür, R.; Giertsen, E.; Guggenheim, B. Automated Fluorescent in Situ Hybridization for the Specific Detection and Quantification of Oral Streptococci in Dental Plaque. J. Microbiol. Methods 2001, 44, 39-47. [CrossRef]

53. Dunbar, S.A.; Ritchie, V.B.; Hoffmeyer, M.R.; Rana, G.S.; Zhang, H. Luminex(R) Multiplex Bead Suspension Arrays for the Detection and Serotyping of Salmonella spp. Methods Mol. Biol. 2015, 1225, 1-27.

54. Gürkan, A.; Tekdal, G.P.; Bostanc1, N.; Belibasakis, G.N. Cytokine, Chemokine, and Growth Factor Levels in Peri-Implant Sulcus During Wound Healing and Osseointegration After Piezosurgical Versus Conventional Implant Site Preparation: Randomized, Controlled, Split-Mouth Trial. J. Periodontol. 2018, 90, 616-626. [CrossRef]

55. Varet, H.; Brillet-Guéguen, L.; Coppée, J.Y.; Dillies, M.A. SARTools: A DESeq2- and EdgeR-Based R Pipeline for Comprehensive Differential Analysis of RNA-Seq Data. PLoS ONE 2016, 11, e0157022. [CrossRef]

56. Zehnder, M.; Rechenberg, D.-K.; Thurnheer, T.; Lüthi-Schaller, H.; Belibasakis, G. FISHing for Gutta-Percha-Adhered Biofilms in Purulent Post-Treatment Apical Periodontitis. Mol. Oral Microbiol. 2017, 32, 226-235. [CrossRef]

57. Thurnheer, T.; Gmür, R.; Guggenheim, B. Multiplex FISH Analysis of a Six-Species Bacterial Biofilm. J. Microbiol. Methods 2004, 56, 37-47. [CrossRef]

58. Paster, B.J.; Boches, S.K.; Galvin, J.L.; Ericson, R.E.; Lau, C.N.; Levanos, V.A.; Sahasrabudhe, A.; Dewhirst, F.E. Bacterial Diversity in Human Subgingival Plaque. J. Bacteriol. 2001, 183, 3770-3783. [CrossRef]

59. Wade, W.G.; Prosdocimi, E.M. Profiling of Oral Bacterial Communities. J. Dent. Res. 2020, 99, 621-629. [CrossRef]

60. Bermejo-Fenoll, A.; Sanchez-Perez, A. Necrotising Periodontal Diseases. Med. Oral Patol. Oral Cir. Bucal. 2004, 9 (Suppl. 114-119), 108-114. [PubMed]

61. Loesche, W.J.; Grossman, N.S. Periodontal Disease as a Specific, Albeit Chronic, Infection: Diagnosis and Treatment. Clin. Microbiol. Rev. 2001, 14, 727-752. [CrossRef] [PubMed]

62. Lopez, R.; Hujoel, P.; Belibasakis, G.N. On Putative Periodontal Pathogens: An Epidemiological Perspective. Virulence 2015, 6, 249-257. [CrossRef] [PubMed]

63. Daims, H.; Brühl, A.; Amann, R.; Schleifer, K.H.; Wagner, M. The Domain-specific Probe EUB338 is Insufficient for the Detection of all Bacteria: Development and Evaluation of a more Comprehensive Probe Set. Syst. Appl. Microbiol. 1999, 22, 434-444. [CrossRef]

64. Contaldo, M.; Lucchese, A.; Romano, A.; Della Vella, F.; Di Stasio, D.; Serpico, R.; Petruzzi, M. Oral Microbiota Features in Subjects with Down Syndrome and Periodontal Diseases: A Systematic Review. Int. J. Mol. Sci. 2021, 22, 9251. [CrossRef]

65. Amano, A.; Kuboniwa, A.M.; Nakagawa, I.; Akiyama, S.; Morisaki, I.; Hamada, S. Prevalence of Specific Genotypes of Porphyromonas gingivalis fimA and Periodontal Health Status. J. Dent. Res. 2000, 79, 1664-1668. [CrossRef]

66. Bostanci, N.; Allaker, R.P.; Belibasakis, G.N.; Rangarajan, M.; Curtis, M.A.; Hughes, F.J.; McKay, I.J. Porphyromonas gingivalis Antagonises Campylobacter rectus Induced Cytokine Production by Human Monocytes. Cytokine 2007, 39, 147-156. [CrossRef]

67. Felix, J.; Savvides, S.N. Mechanisms of Immunomodulation by Mammalian and Viral Decoy Receptors: Insights from Structures Nat. Rev. Immunol. 2017, 17, 112-129. [CrossRef]

68. Male, D.; Brostoff, J.; Roth, D.; Roitt, I. Immunology: With STUDENT CONSULT Online Access, 8th ed.; Elsevier: Edinburgh, UK, 2012.

69. Muñoz-Carrillo, J.L.; Contreras-Cordero, J.F.; Gutiérrez-Coronado, O.; Villalobos-Gutiérrez, P.T.; Ramos-Gracia, L.G.; HernándezReyes, V.E. Cytokine Profiling Plays a Crucial Role in Activating Immune System to Clear Infectious Pathogens. In Immune Response Activation and Immunomodulation; IntechOpen: London, UK, 2018.

70. Abbas, A.K.; Lichtman, A.H.H.; Pillai, S. Cellular and Molecular Immunology: With STUDENT CONSULT Online Access; Elsevier: Philadelphia, PA, USA, 2014.

71. Metcalf, D. The Colony-Stimulating Factors and Cancer. Nat. Rev. Cancer 2010, 10, 425-434. [CrossRef]

72. Hamilton, J.A. Colony-Stimulating Factors in Inflammation and Autoimmunity. Nat. Rev. Immunol. 2008, 8, 533-544. [CrossRef]

73. Khajah, M.; Millen, B.; Cara, D.C.; Waterhouse, C.; McCafferty, D.M. Granulocyte-Macrophage Colony-Stimulating Factor (GM-CSF): A Chemoattractive Agent for Murine Leukocytes in Vivo. J. Leukoc. Biol. 2011, 89, 945-953. [CrossRef]

74. Gomez-Cambronero, J.; Horn, J.; Paul, C.C.; Baumann, M.A. Granulocyte-Macrophage Colony-Stimulating Factor Is a Chemoattractant Cytokine for Human Neutrophils: Involvement of the Ribosomal p70 S6 Kinase Signaling Pathway. J. Immunol. 2003, 171, 6846-6855. [CrossRef]

75. Molineux, G.; Foote, M.; Arvedson, T. Twenty Years of G-CSF Clinical and Nonclinical Discoveries, in Milestones in Drug Therapy; Springer: Basel, Switzerland, 2012.

76. Carulli, G. Effects of Recombinant Human Granulocyte Colony-Stimulating Factor Administration on Neutrophil Phenotype and Functions. Haematologica 1997, 82, 606-616.

77. Kawakami, M.; Tsutsumi, H.; Kumakawa, T.; Abe, H.; Hirai, M.; Kurosawa, S.; Mori, M.; Fukushima, M. Levels of Serum Granulocyte Colony-Stimulating Factor in Patients with Infections. Blood 1990, 76, 1962-1964. [CrossRef] [PubMed] 
78. O'Grady, N.P.; Preas, H.L.; Pugin, J.; Fiuza-Marco, C.; Tropea, M.; Reda, D.; Banks, S.M.; Suffredini, A.F. Local Inflammatory Responses Following Bronchial Endotoxin Instillation in Humans. Am. J. Respir. Crit. Care Med. 2001, 163, 1591-1598. [CrossRef] [PubMed]

79. Bhattacharya, P.; Thiruppathi, M.; Elshabrawy, H.A.; Alharshawi, K.; Kumar, P.; Prabhakar, B.S. GM-CSF: An Immune Modulatory Cytokine that Can Suppress Autoimmunity. Cytokine 2015, 75, 261-271. [CrossRef] [PubMed]

80. Trus, E.; Basta, S.; Gee, K. Who's in Charge Here? Macrophage Colony Stimulating Factor and Granulocyte Macrophage Colony Stimulating Factor: Competing Factors in Macrophage Polarization. Cytokine 2019, 127, 154939. [CrossRef]

81. Hamilton, J.A. Rheumatoid Arthritis: Opposing Actions of Haemopoietic Growth Factors and Slow-Acting Anti-Rheumatic Drugs. Lancet 1993, 342, 536-539. [CrossRef]

82. Yucel-Lindberg, T.; Nilsson, S.; Modéer, T. Signal Transduction Pathways Involved in the Synergistic Stimulation of Prostaglandin Production by Interleukin-1 Beta and Tumor Necrosis Factor Alpha in Human Gingival Fibroblasts. J. Dent. Res. 1999, 78, 61-68. [CrossRef]

83. Zhang, F.; Engebretson, S.P.; Morton, R.S.; Cavanaugh, P.F.; Subbaramaiah, K.; Dannenberg, A.J. The Overexpression of Cyclooxygenase-2 in Chronic Periodontitis. J. Am. Dent. Assoc. 2003, 134, 861-867. [CrossRef]

84. Noguchi, K.; Miyauchi, M.; Oka, H.; Komaki, M.; Somerman, M.J.; Takata, T. Cyclooxygenase-2-Dependent Prostaglandin E(2) Upregulates Interleukin (IL)-1alpha-Induced IL-6 Generation in Mouse Cementoblasts. J. Periodontol. 2007, 78, 135-140. [CrossRef]

85. de Oliveira, R.R.; Schwartz-Filho, H.O.; Novaes, A.B.; Garlet, G.P.; de Souza, R.F.; Taba, M.; Scombatti de Souza, S.L.; Ribeiro, F.J Antimicrobial Photodynamic Therapy in the Non-Surgical Treatment of Aggressive Periodontitis: Cytokine Profile in Gingival Crevicular Fluid, Preliminary Results. J. Periodontol. 2009, 80, 98-105. [CrossRef]

86. Tervahartiala, T.; Koski, H.; Xu, J.-W.; Häyrinen-Immonen, R.; Hietanen, J.; Sorsa, T.; Konttinen, Y. Tumor Necrosis Factor-a and its Receptors, p55 and p75, in Gingiva of Adult Periodontitis. J. Dent. Res. 2001, 80, 1535-1539. [CrossRef]

87. Santos, V.R.; Ribeiro, F.; Lima, J.A.; Napimoga, M.; Bastos, M.F.; Duarte, P.M. Cytokine Levels in Sites of Chronic Periodontitis of Poorly Controlled and Well-Controlled Type 2 Diabetic Subjects. J. Clin. Periodontol. 2010, 37, 1049-1058. [CrossRef]

88. Bastos, M.; Lima, J.; Vieira, P.; Mestnik, M.; Faveri, M.; Duarte, P. TNF-Alpha and IL-4 Levels in Generalized Aggressive Periodontitis Subjects. Oral Dis. 2009, 15, 82-87. [CrossRef]

89. Tamura, M.; Arakaki, N.; Tsubouchi, H.; Takada, H.; Daikuhara, Y. Enhancement of Human Hepatocyte Growth Factor Production by Interleukin-1 Alpha and -1 Beta and Tumor Necrosis Factor-Alpha by Fibroblasts in Culture. J. Biol. Chem 1993, 268, 8140-8145. [CrossRef]

90. Ohnishi, T.; Suwa, M.; Oyama, T.; Arakaki, N.; Torii, M.; Daikuhara, Y. Prostaglandin E2 Predominantly Induces Production of Hepatocyte Growth Factor/Scatter Factor in Human Dental Pulp in Acute Inflammation. J. Dent. Res. 2000, 79, 748-755. [CrossRef]

91. Sugiyama, A.; Ogawa, T.; Daikuhara, Y.; Takada, H. Enhancement of Hepatocyte Growth Factor (Scatter Factor) Production by Human Gingival Fibroblasts in Culture Stimulated with Porphyromonas gingivalis Fimbriae. J. Med. Microbiol. 2000, 49, 319-325. [CrossRef]

92. Iki, K.; Kawahara, K.; Sawamura, S.; Arakaki, R.; Sakuta, T.; Sugiyama, A.; Tamura, H.; Sueda, T.; Hamada, S.; Takada, H. A Novel Component Different from Endotoxin Extracted from Prevotella intermedia ATCC 25611 Activates Lymphoid Cells from C3H/HeJ Mice and Gingival Fibroblasts from Humans. Infect. Immun. 1997, 65, 4531-4538. [CrossRef]

93. Anil, S.; Vellappally, S.; Preethanath, R.S.; Mokeem, S.A.; AlMoharib, H.S.; Patil, S.; Chalisserry, E.; Al Kheraif, A.A. Hepatocyte Growth Factor Levels in the Saliva and Gingival Crevicular Fluid in Smokers with Periodontitis. Dis. Markers 2014, $2014,146974$. [CrossRef]

94. Ohshima, M.; Sakai, A.; Ito, K.; Otsuka, K. Hepatocyte Growth Factor (HGF) in Periodontal Disease: Detection of HGF in Gingival Crevicular Fluid. J. Periodontal Res. 2002, 37, 8-14. [CrossRef]

95. Minty, A.; Chalon, P.; Derocq, J.M.; Dumont, X.; Guillemot, J.C.; Kaghad, M.; Labit, C.; Leplatois, P.; Liauzun, P.; Miloux, B. Interleukin-13 is a New Human Lymphokine Regulating Inflammatory and Immune Responses. Nature 1993, 362, $248-250$. [CrossRef]

96. Beklen, A. Effects of IL-13 on TGF- $\beta$ and MMP-1 in Periodontitis. Biotech. Histochem. 2017, 92, 374-380. [CrossRef]

97. Gonzales, J.R.; Gröger, S.; Haley, G.; Bödeker, R.-H.; Meyle, J. Production of Interleukin-13 is Influenced by the Interleukin-4 -34TT and -590TT Genotype in Patients with Aggressive Periodontitis. Scand. J. Immunol. 2011, 73, 128-134. [CrossRef]

98. Wynn, T.A. IL-13 Effector Functions. Annu. Rev. Immunol. 2003, 21, 425-456. [CrossRef]

99. Liu, C.; Papewalis, C.; Domberg, J.; Scherbaum, W.; Schott, M. Chemokines and Autoimmune Thyroid Diseases. Horm. Metab. Res. 2008, 40, 361-368. [CrossRef]

100. Antonelli, A.; Ferrari, S.M.; Giuggioli, D.; Ferrannini, E.; Ferri, C.; Fallahi, P. Chemokine (C-X-C motif) Ligand (CXCL)10 in Autoimmune Diseases. Autoimmun. Rev. 2014, 13, 272-280. [CrossRef]

101. Smit, M.J.; Verdijk, P.; van der Raaij-Helmer, E.M.H.; Navis, M.; Hensbergen, P.J.; Leurs, R.; Tensen, C.P. CXCR3-Mediated Chemotaxis of Human T Cells is Regulated by a Gi- and Phospholipase C-Dependent Pathway and Not Via Activation of MEK/p44/p42 MAPK Nor Akt/PI-3 Kinase. Blood 2003, 102, 1959-1965. [CrossRef] 
102. de Queiroz, A.C.; Taba, M.; O'Connell, P.A.; da Nóbrega, P.B.; Costa, P.P.; Kawata, V.K.; Trevisan, G.L.; Novaes, A.B.; de Souza, S.L.; Palioto, D.B.; et al. Inflammation Markers in Healthy and Periodontitis Patients: A Preliminary Data Screening. Braz. Dent. J. 2008, 19, 3-8. [CrossRef]

103. Paparo, S.R. The MIG Chemokine in Inflammatory Myopathies. Clin. Ter. 2019, 170, e55-e60.

104. Tecco, S.; Grusovin, M.G.; Sciara, S.; Bova, F.; Pantaleo, G.; Capparé, P. The Association Between Three Attitude-Related Indexes of Oral Hygiene and Secondary Implant Failures: A Retrospective Longitudinal Study. Int. J. Dent. Hyg. 2018, 16, 372-379. [CrossRef]

105. Crespi, R.; Capparè, P.; Gherlone, E. Sinus Floor Elevation by Osteotome: Hand Mallet Versus Electric Mallet. A Prospective Clinical Study. Int. J. Oral Maxillofac. Implant. 2012, 27, 1144-1150.

106. Gherlone, E.; Capparé, P.; Pasciuta, R.; Grusovin, M.G.; Mancini, N.; Burioni, R. Evaluation of Resistance Against Bacterial Microleakage of a New Conical Implant-Abutment Connection Versus Conventional Connections: An in Vitro Study. New Microbiol. 2016, 39, 49-56.

107. Capparè, P.; Tetè, G.; Sberna, M.T.; Panina-Bordignon, P. The Emerging Role of Stem Cells in Regenerative Dentistry. Curr. Gene Ther. 2020, 20, 259-268. [CrossRef] [PubMed] 